\title{
Systemic immune response and virus persistence after foot-and-mouth disease virus infection of naïve cattle and cattle vaccinated with a homologous adenovirus- vectored vaccine
}

\author{
Michael Eschbaumer ${ }^{1,2}$, Carolina Stenfeldt ${ }^{1,2}$, Steven I. Rekant ${ }^{1,2}$, Juan M. Pacheco ${ }^{1}$, Ethan J. Hartwig',
} George R. Smoliga', Mary A. Kenney ${ }^{1}$, William T. Golde', Luis L. Rodriguez ${ }^{1}$ and Jonathan Arzt ${ }^{1 *}$

\begin{abstract}
Background: In order to investigate host factors associated with the establishment of persistent foot-and-mouth disease virus (FMDV) infection, the systemic response to vaccination and challenge was studied in 47 steers. Eighteen steers that had received a recombinant FMDV A vaccine 2 weeks earlier and 29 non-vaccinated steers were challenged by intra-nasopharyngeal deposition of FMDV A24. For up to 35 days after challenge, host factors including complete blood counts with T lymphocyte subsets, type I/III interferon (IFN) activity, neutralizing and total FMDV-specific antibody titers in serum, as well as antibody-secreting cells (in 6 non-vaccinated animals) were characterized in the context of viral infection dynamics.

Results: Vaccination generally induced a strong antibody response. There was a transient peak of FMDV-specific serum IgM in non-vaccinated animals after challenge, while IgM levels in vaccinated animals did not increase further. Both groups had a lasting increase of specific $\lg G$ and neutralizing antibody after challenge.

Substantial systemic IFN activity in non-vaccinated animals coincided with viremia, and no IFN or viremia was detected in vaccinated animals. After challenge, circulating lymphocytes decreased in non-vaccinated animals, coincident with viremia, IFN activity, and clinical disease, whereas lymphocyte and monocyte counts in vaccinated animals were unaffected by vaccination but transiently increased after challenge. The $\mathrm{CD} 4^{+} / \mathrm{CD} 8^{+} \mathrm{T}$ cell ratio in non-vaccinated animals increased during acute infection, driven by an absolute decrease of CD8 ${ }^{+}$cells.

Conclusions: The incidence of FMDV persistence was $61.5 \%$ in non-vaccinated and $54.5 \%$ in vaccinated animals. Overall, the systemic factors examined were not associated with the FMDV carrier/non-carrier divergence; however, significant differences were identified between responses of non-vaccinated and vaccinated cattle.
\end{abstract}

Keywords: FMDV, Vaccination, Persistence, Carrier, Flow cytometry, Lymphopenia, Interferon, ELISA, ELISPOT

\footnotetext{
* Correspondence: jonathan.arzt@ars.usda.gov

${ }^{1}$ United States Department of Agriculture (USDA), Plum Island Animal

Disease Center (PIADC), Foreign Animal Disease Research Unit (FADRU),

Agricultural Research Service (ARS), P.O. Box 848, Greenport, NY 11944, USA

Full list of author information is available at the end of the article
} 


\section{Background}

Foot-and-mouth disease virus (FMDV; family Picornaviridae; genus Aphthovirus) causes a highly contagious, acute disease of cloven-hoofed animals, with fever, lameness, and vesicular lesions of the feet, tongue, muzzle, and teats reviewed in [1-3]. Foot-and-mouth disease (FMD) is a difficult and expensive disease to control and eradicate due to its wide host range, low minimum infectious dose, rapid rate of replication, high level of viral shedding, and multiple modes of transmission $[1,3]$. The situation is further complicated by an important subclinical divergence that occurs after acute infection of ruminants: some animals remain subclinically infected for up to 3 years ("FMDV carriers") ([2], reviewed in $[4,5]$ ), while others completely clear the virus within 1 to 2 weeks ("non-carriers"). The definition of an FMDV carrier established by the World Organisation for Animal Health (OIE) is an animal from which infectious FMDV can be recovered at greater than 28 days after infection [6].

The bovine nasopharynx [7-12] and regional lymph nodes [13] have been identified as sites of this persistence, but it is poorly understood how FMDV evades clearance by the host immune response at these sites [14]. It is also unknown whether there are pre-existent factors or patterns in the virus-host interaction during and after acute infection that can be used to predict or influence the ultimate outcome of virus clearance versus persistence.

Type I and type III interferons (IFN) are important parts of the early innate immune response to viral infection and are often crucial in controlling or eliminating infection (reviewed in [15]). All cells in the body are responsive to type I IFNs, whereas the type III IFN receptor is mostly restricted to gastrointestinal and airway epithelia [16]. Several reports have demonstrated strong IFN activity during FMDV infection in cattle using an Mx/CAT reporter system which does not differentiate between IFN type I and type III [17-22]. Using this method, type I/III IFN activity has been found in circulating plasmacytoid dendritic cells (pDCs) $[18,23]$ and in tissues at sites of virus replication [22]. However, it is unclear how much of the systemically detected IFN originates within the vasculature as opposed to from sites of infection in tissues.

In pigs, FMDV infection leads to lymphopenia and immune suppression, manifested as a significant loss of circulating T cells $[24,25]$. Significant lymphopenia during acute FMDV infection of cattle has been described $[20,26]$, but other studies have reported that no changes occur in total circulating leukocytes or relative lymphocyte subpopulations $[27,28]$. One report concluded that the T-cell response to mitogen and non-FMDV antigens was not impaired during acute FMDV infection, but no FMDV-specific T-cell responses were detected [28].
In earlier experiments, the depletion of $\mathrm{CD}^{+}$cells in vivo significantly reduced neutralizing antibody titers and delayed class switching in cattle vaccinated with inactivated FMDV [29]. However, in non-vaccinated cattle, $\mathrm{CD} 4^{+}$depletion before FMDV infection had no effect on clinical signs, the induction of neutralizing antibodies, or the acute clearance of virus from the circulation [27]. These and other studies have concluded that the antigenic structure of the FMDV capsid, the high local antigen concentration, and the strong cytokine response during acute infection likely are key factors in the efficient induction of $\mathrm{T}$ cell-independent antibody responses $[29,30]$.

$\mathrm{CD}^{+}$cytotoxic $\mathrm{T}$ lymphocytes (CTLs) from vaccinated pigs are capable of selectively killing FMDV-infected cells in vitro [31], and infection of pigs with FMDV also leads to a clear CTL response [32]. However, in cattle, partial depletion of $\mathrm{CD}^{+}$cells did not affect the resolution of acute FMDV infection [27]. Given that the acute phase of an FMDV infection is concluded before a significant adaptive CTL response can be mounted [28], it is likely that the control of the infection is mediated by a T-cellindependent neutralizing antibody response and type $\mathrm{I} /$ III interferon signaling. Overall, the role of bovine antigen-specific $\mathrm{T}$ cells in FMDV infection remains unresolved, and it is unclear how FMDV evades the CTL response during persistent infection.

The kinetics of circulating FMDV-specific antibodysecreting cells in the context of antibody levels and neutralizing activity have not yet been examined. FMDV infection generally elicits a rapid, strong, and lasting antibody response. Coincident with the first detection of antibody there is a rapid clearance of virus from the circulation and a more gradual reduction of virus shedding. Although circulating antibodies are generally believed to be the primary mediators of immunity after infection or vaccination [3], it is well known that vaccines prevent viremia and generalized disease, but not primary local infection, e.g., in the pharynx. Several studies have reported shedding of infectious FMDV in nasal, oral, or oropharyngeal fluids of vaccinated animals following virus exposure [10,33-37], which is consistent with primary infection of the upper respiratory or gastrointestinal tracts. Virus replication in the nasopharyngeal mucosa of vaccinated animals in the present study has been demonstrated in a separate publication [38]. The occurrence of persistent, asymptomatic FMDV infection in vaccinated cattle $[9,10,34,36,37,39,40]$ provides further unequivocal evidence that vaccination does not prevent primary infection.

Similarly, antibodies are ineffective in clearing virus from the pharynx of carrier ruminants [4], and substantial antibody levels - in serum as well as in secretions-have been reported in animals that remained persistently infected with FMDV [21, 41-43]. In vaccinated animals, 
protection against challenge is correlated with neutralizing antibody in circulation, but low antibody levels can also be protective $[35,44,45]$ and animals with high neutralizing titers can develop disease after challenge [37].

The overarching goal of the present study was to elucidate systemic host factors associated with the response to FMDV in cattle during early and late stages of infection and to categorize these responses in the context of vaccination status and carrier-state divergence. For this purpose, serological and hematological parameters as well as lymphocyte sub-populations were investigated in vaccinated and non-vaccinated cattle from the day of FMDV vaccination and/or infection to the persistent/ recovered phase. Trends associated with acute disease, vaccination, and the development of the FMDV-carrier state were examined in the context of clinical, virological, and serological data collected from the same animals.

\section{Methods \\ Animals}

Forty-seven Holstein steers ( 6 to 8 months, $\sim 200 \mathrm{~kg}$ ) were obtained from an experimental livestock provider (Thomas D. Morris Inc., Reisterstown, MD, USA) accredited by the Association for Assessment and Accreditation of Laboratory Animal Care International and registered with the United States Department of Agriculture (USDA). The animals were housed together in a BSL-3-Ag animal facility from the time of arrival until euthanasia, and were given an acclimation period of 2 weeks before the start of the experiment. The health status of all animals was assessed daily throughout the study period. Based on daily clinical assessments, analgesics and anti-inflammatory drugs (flunixin meglumine, $1.1-2.2 \mathrm{mg} / \mathrm{kg}$; butorphanol tartrate, $0.1 \mathrm{mg} / \mathrm{kg}$ ) were administered to mitigate pain associated with severe clinical FMD as needed. Steers were sedated with xylazine (intramuscular, $0.22 \mathrm{mg} / \mathrm{kg}$ ) for inoculations and clinical exams; after the procedure, the sedation was reversed with tolazoline (intravenous, $2 \mathrm{mg} / \mathrm{kg}$ ).

\section{Vaccination}

Two weeks before infection, eighteen of the 47 steers were immunized using a recently licensed recombinant FMD serotype A vaccine (USDA product code 1FM.1R0; manufactured by Antelope Valley Bios, Lincoln, NE, USA). This vaccine contains the $\mathrm{P} 1-2 \mathrm{~A}$ and 3 Cpro coding regions from FMDV A24 Cruzeiro within a replicationdeficient human adenovirus serotype 5 vector [46]. The steers were intramuscularly injected with the product release dose in a $2 \mathrm{~mL}$ total volume containing commercially available adjuvant (product \#7010101, VaxLiant, Lincoln, NE, USA).

\section{Challenge infection}

All animals were clinically evaluated and sampled prior to inoculation, to ensure their FMDV-free status and the absence of elevated systemic type I/III IFN levels that could interfere with initial FMDV replication. On day 0 of the experiment, all animals were inoculated with $10^{5}$ infectious doses (titrated in bovine tongue epithelium) [6] of FMDV $\mathrm{A}_{24}$ Cruzeiro [47] in $2 \mathrm{~mL}$ of minimum essential medium (MEM) with 25 mM HEPES by intranasopharyngeal (INP) deposition [38, 48]. The successful deposition of virus was confirmed in all animals by collection of nasal and oral fluids after removal of the inoculation catheter (data not shown).

\section{Clinical evaluation}

From the day of challenge until 10 days post inoculation (dpi), clinical scores were recorded on a scale from 0 to 5 accounting for presence of FMD vesicles on each foot or anywhere on the head (oral cavity or nasal epithelia) [12]. Clinical examinations with sedation were performed daily in non-vaccinated animals and every other day in vaccinated animals, either throughout the first $10 \mathrm{dpi}$, or until the animal had reached full clinical score. Rectal body temperatures were taken every day for the entire duration of the experiment.

\section{Euthanasia and tissue collection}

A subset of study animals were euthanized at predetermined time points during acute and post-acute phases of infection (0 to $14 \mathrm{dpi}$ ) for detailed tissue-based pathogenesis studies which have been presented in separate publications $[12,38]$. All samples and data collected before necropsy, however, are included herein. Specifically, four non-vaccinated animals were euthanized on $1 \mathrm{dpi}$, and two each on 2, 3, 4, 7, 10, and 14 dpi. Among vaccinated animals, two animals were euthanized on each of 1, 2, and $3 \mathrm{dpi}$, and one on $14 \mathrm{dpi}$ (see Fig. 1). Sodium pentobarbital (intravenous, $86 \mathrm{mg} / \mathrm{kg}$ ) was used for all euthanasias.

The OIE defines FMDV carriers as animals in which the virus persists for more than 28 days after infection [6]. For the animals in this study, however, it was found that the persistence status could be reliably determined by $21 \mathrm{dpi}$ (see Results section for details).

Since the FMDV carrier status was not determined for animals euthanized earlier than $21 \mathrm{dpi}$, these animals were excluded from graphical and statistical analyses that discriminated animals by persistence status; however, these animals were included in all analyses that did not require their persistence status to be defined. Twenty-four out of 47 animals (13 non-vaccinated and 11 vaccinated) were kept alive beyond $21 \mathrm{dpi}$, which was determined to be the threshold at which it was possible to consistently conclude from oropharyngeal fluid samples whether an animal had 


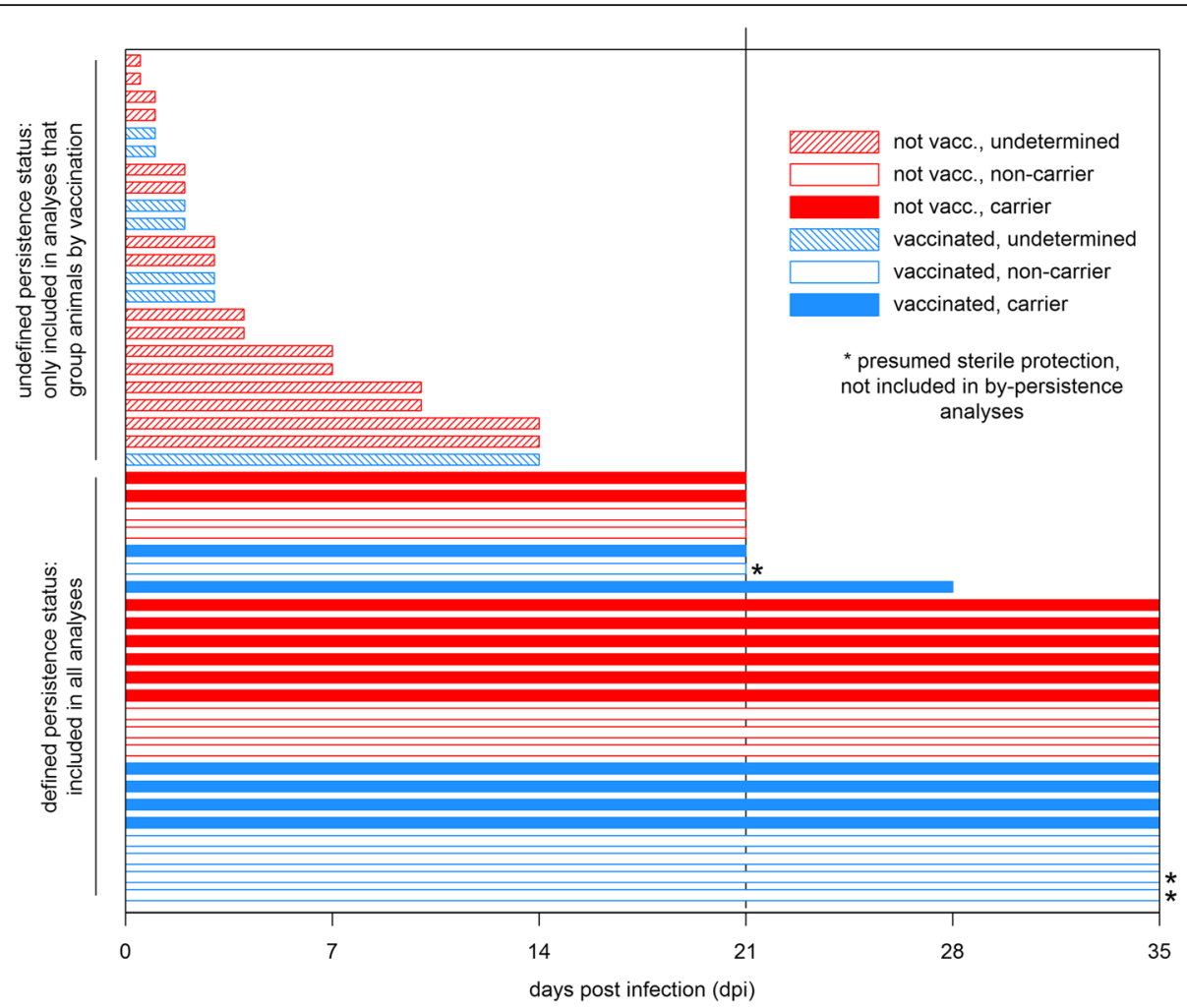

Fig. 1 Overview of the experimental timeline. Each bar represents one animal, with the length of the bar corresponding to the time the animal remained in the experiment after challenge infection ( $21 \mathrm{dpi}$, the revised cut-off by which FMDV persistence status could be determined, is marked by a vertical line). Non-vaccinated animals are shown in red, vaccinated animals in blue. Solid-colored bars are FMDV carriers, unfilled bars are non-carriers. Striped bars are used when the persistence status of an animal could not be determined because it was euthanized before $21 \mathrm{dpi}$. Asterisks mark the three animals without convincing evidence of infection (see Results section for details)

cleared the infection or entered the FMDV carrier state. With the exception of three vaccinated animals in which infection could not be confirmed (see Results section for details), all animals that were kept alive to 21 dpi or longer were included in all analyses.

\section{Blood and probang samples}

Blood was collected from the jugular vein on the day of vaccination (immediately before), on days 4 and 7 postvaccination $(\mathrm{dpv})$, on the day of challenge (immediately before), then daily for the first ten dpi and afterwards weekly until 35 dpi. Samples were collected in BD Vacutainer ${ }^{\circledR}$ tubes containing either $\mathrm{K}_{2} \mathrm{EDTA}$ for hematology, heparin for PBMC separation, or serum-separator gel. Starting on $7 \mathrm{dpi}(21 \mathrm{dpv})$ in vaccinated animals and 14 $\mathrm{dpi}$ in non-vaccinated animals, oropharyngeal fluids (OPF) were collected by probang cup [49] two times per week. Probang cup contents were mixed with an equal volume of cold MEM with $25 \mathrm{mM}$ HEPES immediately after collection and then kept on ice. Upon arrival in the laboratory, serum tubes were centrifuged for harvesting $\left(10 \mathrm{~min}\right.$ at $1000 \times \mathrm{g}$ and $4{ }^{\circ} \mathrm{C}$ ), and OPF samples were immediately processed as described previously [10], including treatment with 1,1,2-trichlorofluoroethane (TTE) to reactivate antibody-bound virus [50].

The PBMC preparation, surface marker staining, and flow cytometric data collection have been described previously [51]. Briefly, for separation of PBMCs, $18 \mathrm{~mL}$ of fresh heparinized blood were diluted in Dulbecco's phosphatebuffered saline (PBS; Life Technologies, Carlsbad, CA, USA), underlaid with Histopaque 1083 (Sigma-Aldrich, St. Louis, MO, USA), and centrifuged. Harvested PBMCs were washed twice with PBS, counted, and resuspended at a concentration of $10^{7}$ cells $/ \mathrm{mL}$ in either fetal bovine serum (FBS; GE Healthcare Life Sciences, Logan, UT, USA) with $10 \%(\mathrm{v} / \mathrm{v})$ dimethyl sulfoxide (Sigma-Aldrich) for freezing (for flow cytometry) or in ELISPOT media (RPMI1640 with antibiotics, $0.1 \mathrm{mM}$ non-essential amino acids, $2 \mathrm{mM}$ L-glutamine, $10 \mathrm{mM}$ HEPES, $1 \mathrm{mM}$ sodium pyruvate [all Life Technologies], and $10 \%$ FBS) for immediate use. Frozen cells were stored at $-70{ }^{\circ} \mathrm{C}$ for no longer than thirty days before flow cytometry analysis.

\section{FMDV RNA detection and virus isolation}

Real-time RT-PCR and virus isolation for FMDV detection in serum and OPF were performed as previously described 
[52]. Briefly, FMDV viral RNA was quantified by real-time RT-PCR targeting the 3D region of the FMDV genome [53] with forward and reverse primers adapted from Rasmussen et al. [54]. Samples with cycle threshold $\left(C_{t}\right)$ values lower than 45 were considered positive. Serial 10-fold dilutions of in vitro synthesized FMDV RNA of known concentration were used to convert $C_{t}$ values to FMDV RNA genome copy numbers $(\mathrm{GCN})$ per $\mathrm{mL}$ of sample. After the conversion, the cut-off $\mathrm{C}_{\mathrm{t}}$ value corresponded to a detection limit of $1.57 \log _{10}$ FMDV GCN/mL.

\section{Type I/III IFN bioassay}

Type I/III IFN activity in serum was quantified using the $\mathrm{Mx} / \mathrm{CAT}$ reporter assay as previously described [22]. Briefly, serum samples collected during the first 10 days after challenge were incubated for $24 \mathrm{~h}$ with recombinant Madin-Darby bovine kidney cells that express chloramphenicol acetyltransferase (CAT) under the control of an Mx1 promoter [17]. CAT expression in the cells was measured with a commercially available ELISA kit (Roche Diagnostics, Indianapolis, IN, USA), and IFN levels in unknown samples were derived from a standard curve of serial dilutions of recombinant human interferon- $\alpha$ 2a with known potency (PBL Assay Science, Piscataway, NJ, USA) that was run in parallel. Results are reported as international units (IU) of IFN per $\mathrm{mL}$ of serum. The Mx/CAT assay does not distinguish between type I and type III interferon [20].

\section{Hematology}

For each whole blood sample from all animals, a complete blood count $(\mathrm{CBC})$ was performed on the same day with a Hemavet 950FS veterinary hematology system (Drew Scientific, Waterbury, CT, USA), following the manufacturer's instructions. High and low values were flagged by the analyzer based on factory-set normal limits. Among the blood parameters reported by the analyzer, only the total white blood cell (WBC) count and its principal components are reported here (in $1000 \mathrm{~s}[\mathrm{~K}]$ of cells per $\mu \mathrm{L}$ of blood). The WBC count is the sum of five subpopulations, with neutrophils, lymphocytes, and monocytes together comprising over $90 \%$ of all circulating white blood cells [55]. The bovine reference ranges are 600 to 4000 neutrophils, 2500 to 7500 lymphocytes, and 0 to 900 monocytes per $\mu \mathrm{L}$ of blood [56].

\section{Flow cytometry}

PBMCs from all animals were evaluated by flow cytometry. Cells were thawed in a water bath at $37{ }^{\circ} \mathrm{C}$, slowly diluted in warm RPMI-1640 media with $10 \%$ FBS, and washed twice with PBS [57]. All samples were stained in duplicate; first with an amine-reactive dye (LIVE/ DEAD $^{\circ}$ Fixable Yellow; Life Technologies), then with monoclonal antibodies against bovine CD3 (MM1A,
$\mathrm{IgG}_{1}$, Washington State University, Pullman, WA, USA), the $\delta$ chain of the $\gamma \delta \mathrm{T}$ cell receptor $\left(\mathrm{GB} 21 \mathrm{~A}, \mathrm{IgG}_{2 \mathrm{~b}}\right.$, Washington State University), CD4 (CC8, IgG ${ }_{2 a}$, conjugated with FITC, Bio-Rad, Hercules, CA, USA), and CD8 (CC63, IgG ${ }_{2 \mathrm{a}}$, Alexa Fluor ${ }^{\circ}$ 647, Bio-Rad), and finally with polyclonal goat antibodies against murine $\operatorname{IgG}_{1}$ (allophycocyanin-cyanine7; SouthernBiotech, Birmingham, AL, USA) and $\operatorname{IgG}_{2 b}$ (R-phycoerythrin; SouthernBiotech). Compensation controls and fluorescence-minus-one controls were included for each antibody/dye combination. After each staining step, cells were washed twice in cold FACS buffer (PBS with $0.3 \%[\mathrm{v} / \mathrm{v}]$ bovine serum albumin fraction $\mathrm{V}$ [Life Technologies] and $0.1 \%[\mathrm{w} / \mathrm{v}$ ] sodium azide).

Stained cells were analyzed in a three-laser LSR II flow cytometer (BD). Initially, events were gated based on forward and side scatter, equal pulse height/area ratio (for single-cell selection), as well as live/dead staining behavior, with low dye uptake considered indicative of membrane integrity and cell viability [58]. The boundaries of a morphological lymphocyte gate (defined by forward and side scatter) were established by backgating from CD3. Among all live cells in that gate, $T$ lymphocytes were then identified by $\mathrm{CD}^{+}$staining. At least 10000 $\mathrm{CD}^{+}$cells were evaluated per sample. $\mathrm{CD}^{+} \gamma \delta \mathrm{TCR}^{-}$cells were presumed to be $\alpha \beta$ T lymphocytes, and were examined for CD4 and CD8 expression. All surface marker gating was done automatically with "snap to" interval gates in single-parameter histograms in BD FACSDiva 8.

The flow cytometer only measures the relative quantities (percent abundance) of $\mathrm{T}$ lymphocyte subsets but does not provide absolute cell counts. Because percent abundance can be misleading when assessing the change in a population of cells over different experimental conditions [59], the flow cytometry and hematology data were combined [60] to obtain absolute counts of the $\mathrm{CD} 4^{+}$and $\mathrm{CD} 8^{+} \alpha \beta$ T lymphocyte subpopulations. The absolute number of cells in each subpopulation was calculated based on the complete blood count obtained with the Hemavet analyzer as described by Riondato et al. [61]. Briefly, the total lymphocyte counts per $\mathrm{mL}$ of peripheral blood were assigned to the morphological lymphocyte gate on the flow cytometer. Absolute numbers for the subpopulations were then obtained by serially applying the percentage-of-parent values to this total count, beginning with the CD3 gate. Absolute counts are reported as number of cells per $\mu \mathrm{L}$ of blood.

\section{Humoral immunity}

All animals that survived for at least 21 days after challenge were included in the serological analyses; animals that were euthanized at earlier time points were not included. 


\section{Serum neutralization test (SNT)}

FMDV-neutralizing antibody titers were determined for serum samples taken at -14 and $-7 \mathrm{dpi}$ (vaccinated animals only; 0 and $7 \mathrm{dpv}$, respectively), and at $0,7,14$, 21,28 , and $35 \mathrm{dpi}$ for all animals. Sera were heat inactivated for $30 \mathrm{~min}$ at $56{ }^{\circ} \mathrm{C}$ and used in a microtiter neutralization assay. Serial fourfold dilutions of serum (in MEM with $25 \mathrm{mM}$ HEPES) on 96-well plates (from an initial dilution of $1 / 8$ down to $1 / 32768$ ) were incubated with $10050 \%$ tissue culture infective doses $\left(\mathrm{TCID}_{50}\right)$ of FMDV A24 Cruzeiro for $1 \mathrm{~h}$ at $37{ }^{\circ} \mathrm{C}$ and $5 \% \mathrm{CO}_{2}$. Freshly trypsinized LFBK- $\alpha$ V $\beta 6$ cells $[62,63]$ were resuspended in MEM with $25 \mathrm{mM}$ HEPES, $4 \times 10^{4}$ cells/well were added to the plates, and the plates were incubated for another $72 \mathrm{~h}$ at $37{ }^{\circ} \mathrm{C}$ and $5 \% \mathrm{CO}_{2}$. After microscopic evaluation of cell monolayers, the plates were treated with crystal violet dissolved in tissue fixative (HistoChoice; AMRESCO, Solon, OH, USA), then washed and air-dried before cytopathic effect was again evaluated visually. Titers were calculated as the reciprocal of the highest dilution of serum that fully neutralized the virus in $50 \%$ of replicate wells.

\section{FMDV-specific antibody ELISAs}

Serum samples were collected on days $-14,-10,-7$ (vaccinated animals only), 0 to 10,14, and 21 after challenge infection and were used without prior heat inactivation. An indirect double antibody sandwich ELISA was developed for the detection of FMDV-specific IgM and IgG in serum. Optimal concentrations of reagents were determined by checkerboard titration. Each reagent was added at a volume of $100 \mu \mathrm{l}$ per well, except where indicated. All incubations were at $37{ }^{\circ} \mathrm{C}$ for an hour, shaking, except where indicated. All washes were performed four times with PBST, $300 \mu$ per well. All dilutions were performed in blocking buffer (BB, $10 \%$ normal horse serum in PBST) except where indicated. Immulon $2 \mathrm{HB}$ plates (Thermo Scientific) were coated with anti-FMDV-A polyclonal rabbit serum (Pirbright Institute, Pirbright, United Kingdom) at a dilution of $1 / 1000$ in fresh carbonate/bicarbonate buffer $(0.05 \mathrm{M}$, $\mathrm{pH}$ 9.6, Sigma-Aldrich) by incubation overnight at $4{ }^{\circ} \mathrm{C}$. After washing, plates were incubated with $200 \mu \mathrm{l}$ per well of BB. After emptying plates, they were incubated with positive and negative (made by BEI inactivation of mockand virus-infected cells) antigen preparations that were added to negative and positive columns, respectively. After washing, serum samples were added at a dilution of $1 / 100$ for IgM detection, $100 \mu \mathrm{L}$ each on negative- and positiveantigen coated wells. The same was true for IgG detection, but at a dilution of $1 / 500$. In each plate, standard positive and negative sera were included. The standard negative serum was obtained from animals that were FMDVantibody free. Standard positive sera were chosen during the initial phase of the development of the assays because of their high titer and high maximum absorbance value. After incubation and washing, the bound bovine antibodies were detected using sheep anti-bovine IgM or sheep anti-bovine IgG heavy chain directly conjugated to horseradish peroxidase (A10-101P or A10118P, respectively; Bethyl Laboratories, Inc., Montgomery, Texas). After incubation and washing, ELISA was completed by addition of substrate solution (SureBlue peroxidase substrate, Kirkegaard \& Perry Laboratories [KPL], Gaithersburg, MD, USA) and stopped after $10 \mathrm{~min}$ at room temperature by addition of $50 \mu \mathrm{l} /$ well of stop solution (BlueStop; KPL). Absorbance was measured with an ELx808 microplate reader (BioTek, Winooski, VT, USA) using a 630-nm filter. For each sample, a net OD was calculated by subtracting the reading of the negativeantigen well from the positive-antigen well. For each plate, the net ODs of test samples were then divided by the net OD of the positive control sample on the same plate. Identical aliquots of the same positive control were used for all plates, and results are reported as fractions of the net OD of the positive control (nFPC). To further correct for non-specific reactivity, the nFPC value of the sample taken on the day of first exposure to FMDV (either vaccination or challenge) was subtracted from the nFPC values of all subsequent samples of the same animal.

\section{FMDV-specific B-cell ELISPOT}

FMDV-specific antibody-secreting-cell counts from six non-vaccinated animals that survived until 35 dpi were obtained by ELISPOT. Filter plates (EMD Millipore) were coated with monoclonal antibodies against bovine IgM (IL-A30; 1/1000), IgG 1 (IL-A60; 1/500) or IgG (IL-A74; 1/25) (International Livestock Research Institute, Nairobi, Kenya) diluted in fresh carbonate/bicarbonate buffer (0.05 M, pH 9.6, Sigma-Aldrich), incubated overnight at $4{ }^{\circ} \mathrm{C}$, and washed and blocked with ELISPOT media (supplemented RPMI-1640 with $12 \%$ horse serum). Fresh PBMCs were serially diluted in ELISPOT media, and $5 \times 10^{5}, 2.5 \times 10^{5}$ and $1.25 \times 10^{5}$ cells from each sample were seeded in duplicate wells on the same plate, together with a media-only control. After overnight incubation at $37{ }^{\circ} \mathrm{C}$ with $5 \% \mathrm{CO}_{2}$ and thorough washing with PBS with $0.1 \%$ polysorbate $\left(\mathrm{TWEEN}^{\bullet}\right) 20$ (PBST) in an automated plate washer, biotinylated FMDV A24 Cruzeiro antigen (1/500 in PBST) was added to the plates. After a 1-h incubation at room temperature and further washing, HRP-conjugated neutravidin was added at a dilution of $1 / 1000$ (in PBST), and the plates were incubated for $1 \mathrm{~h}$ at room temperature and washed again. Captured FMDV antigen was visualized with TrueBlue peroxidase substrate (KPL) and spots were counted with an ImmunoSpot Analyzer (Cellular Technology Limited, Shaker Heights, OH, USA). Spot counts were normalized 
to the total input of PBMCs, and the IgM count as well as the combined $\operatorname{IgG}_{1}$ and $\operatorname{IgG} G_{2}$ counts were used for comparison with the FMDV antibody ELISA results.

\section{Statistical analysis of hematology and flow cytometry data}

For data analysis, animals were grouped by vaccination or persistence status. Twenty-four animals remained for at least 3 weeks after challenge and were classified as FMDV carriers or non-carriers based on virus isolation results from TTE-treated probang samples. Data were graphed and analyzed with Excel (Microsoft, Redmond, WA, USA) and the R statistical environment [64], particularly the ggplot2 package [65]. Group means are generally annotated with their $95 \%$ confidence intervals (CI95) to facilitate visual comparisons between groups. For group sizes of 3 or fewer, or where between-group comparisons are not meaningful, standard deviations are shown instead.

The hematology and flow cytometry data were analyzed in $\mathrm{R}$ with linear mixed-effects models as implemented in lme4 [66], using the car, phia, and lsmeans packages for post-hoc analyses of specific linear combinations of factor levels. Two models were built for each outcome variable (white blood cells, neutrophils, lymphocytes, monocytes for hematology, and $\mathrm{CD}^{+}, \mathrm{CD}^{+}$ $\gamma \delta \mathrm{TCR}^{-} \mathrm{CD}^{+}, \mathrm{CD}^{+} \gamma \delta \mathrm{TCR}^{-} \mathrm{CD} 8^{+}$for flow cytometry), one with only vaccination status, time, and their interaction term as fixed effects, and another that additionally included persistence status and all interactions between the main effects. This dual approach was chosen because information on persistence status was only available for half of the animals in the study. Animal ID was included as a random effect in all models. For flow cytometry outcome variables, intercepts and slopes were allowed to vary between animals (random intercept and slope), whereas hematology models only had random intercepts.

Where an initial ANOVA (Type II Wald chi-square tests) found significant interactions between status (by vaccination or persistence) and time after infection, pairwise contrasts for the levels of the status factor (vaccination or persistence) were evaluated for each level of the time factor - i.e., difference between vaccinated/non-vaccinated or persistent/non-persistent for each day. Changes in an outcome variable over time were evaluated with custom contrasts (e.g., dpi1 - dpi0) for each level of a status factor; similarly, the effect of time alone was evaluated by averaging across both levels of the status factor and applying the custom contrasts. $P$-values from linear hypothesis tests on the models are reported approximately; any $p$-value $<0.05$ was considered significant.

For the association between viremia and type I/III IFN activity in serum, the test statistic was calculated using Pearson's product moment correlation coefficient.
The asymptotic $95 \%$ confidence interval is based on Fisher's Z transform.

The difference between absolute $\mathrm{CD}^{+}$and $\mathrm{CD}^{+} \alpha \beta$ $\mathrm{T}$ cell counts in non-vaccinated animals before and after challenge ( 0 vs. 5 dpi) was evaluated with a paired $t$-test. The variance was estimated separately for both groups and the Satterthwaite approximation to the degrees of freedom was used. Exact $p$-values are reported for the $t$-test.

\section{Results \\ FMDV carrier/non-carrier divergence}

The overarching goal of this work was to investigate systemic trends associated with 2 categorical factors: vaccination status at the start of the experiment and FMDV carrier status determined at the end of the study. Animals are defined and stratified as "carrier", "non-carrier", or "undetermined" for the entire study based on their final status at the end of the experiment (Fig. 1).

The OIE defines FMDV carriers as animals in which the virus persists for more than 28 days after infection [6]. In the present study, however, all probang samples from non-carriers were virus-negative by $21 \mathrm{dpi}$ and remained negative, whereas all animals that were viruspositive in their 21-dpi probangs remained virus-positive until $28 \mathrm{dpi}$ and beyond; there was no change in viral shedding in probangs in any animal between $21 \mathrm{dpi}$ and the end of the experiment. Thus, for the purposes of this study, FMDV persistence was defined by sustained detection of infectious FMDV in probang samples until at least $21 \mathrm{dpi}$, or until the day of necropsy, whichever was later. Using this definition, 8 out of 13 non-vaccinated animals (61.5\%) which had survived until or past $21 \mathrm{dpi}$ were determined to be persistently infected carriers, whereas 5 out of 13 non-vaccinated animals (38.5\%) had successfully cleared the infection. Of 11 vaccinated animals, 6 were carriers (54.5\%) and 5 non-carriers (45.5\%). Animals that were euthanized before $21 \mathrm{dpi}$ were assigned an "undetermined" persistence status.

The vaccinated non-carrier group was further segregated into two distinct categories based on the observation that three animals lacked convincing virological evidence of infection. All vaccinated non-carrier animals were similar in that there was no detectable viral RNA or infectious virus in OPF, nor was any infectious virus found in tissue samples taken at necropsy. However, two out of the five vaccinated non-carriers had FMDV RNA in nasopharyngeal tissues at 21 or $35 \mathrm{dpi}$, indicating previous infection, while the other three did not [12]. Additionally, the three tissue-RNA-negative cattle did not seroconvert against FMDV non-structural proteins, while all other vaccinated and non-vaccinated non-carriers did (not shown). Taken together, this was considered an 
indication of possible sterile protection, and on this basis, the animals were treated separately and not included with the other non-carriers except for the total count. Specifically, these animals were included in all analyses that stratify animals by vaccination status but were excluded from all analyses that stratify animals by persistence status.

\section{Clinical disease, viremia, and type I/III IFN response}

All non-vaccinated steers developed moderate to severe clinical FMD after virus exposure (Fig. 2a). Characteristic lesions were seen in and around the mouth, including vesicles on the tongue and dental pad as well as on the skin around nostrils and lips. Foot lesions, including vesicles in the interdigital clefts and on coronary bands were often accompanied by moderate lameness. Vesicular lesions first appeared between 2 and 6 dpi (generally on the first day after the onset of detectable viremia) and resolved within approximately 10 days. None of the vaccinated steers developed clinical FMD after challenge (Fig. 2b).

Viremia (defined by presence of viral RNA in serum) was detected in all non-vaccinated steers after virus challenge. The earliest detection of FMDV RNA occurred between 1 and 5 dpi (mean time to initial detection: 3 days), with levels again declining below assay detection limits after four to six days of detection. The peak of mean viremia $\left(6.7 \log _{10} \mathrm{FMDV} \mathrm{GCN} / \mathrm{mL}\right)$ across all non-vaccinated animals occurred on $5 \mathrm{dpi}$. Viremia and type I/III IFN activity in serum were significantly correlated $(r=0.53[0.37 ; 0.66], p<0.01)$, and peak viremia coincided with peak type I/III IFN activity (Fig. 2a). No difference was seen in clinical disease, the magnitude of the IFN response, or the level of viremia between the groups of animals that subsequently diverged into carriers and non-carriers. FMDV RNA was not detected in sera of any of the vaccinated steers at any time, and there was no detectable type I/III IFN activity in the serum of

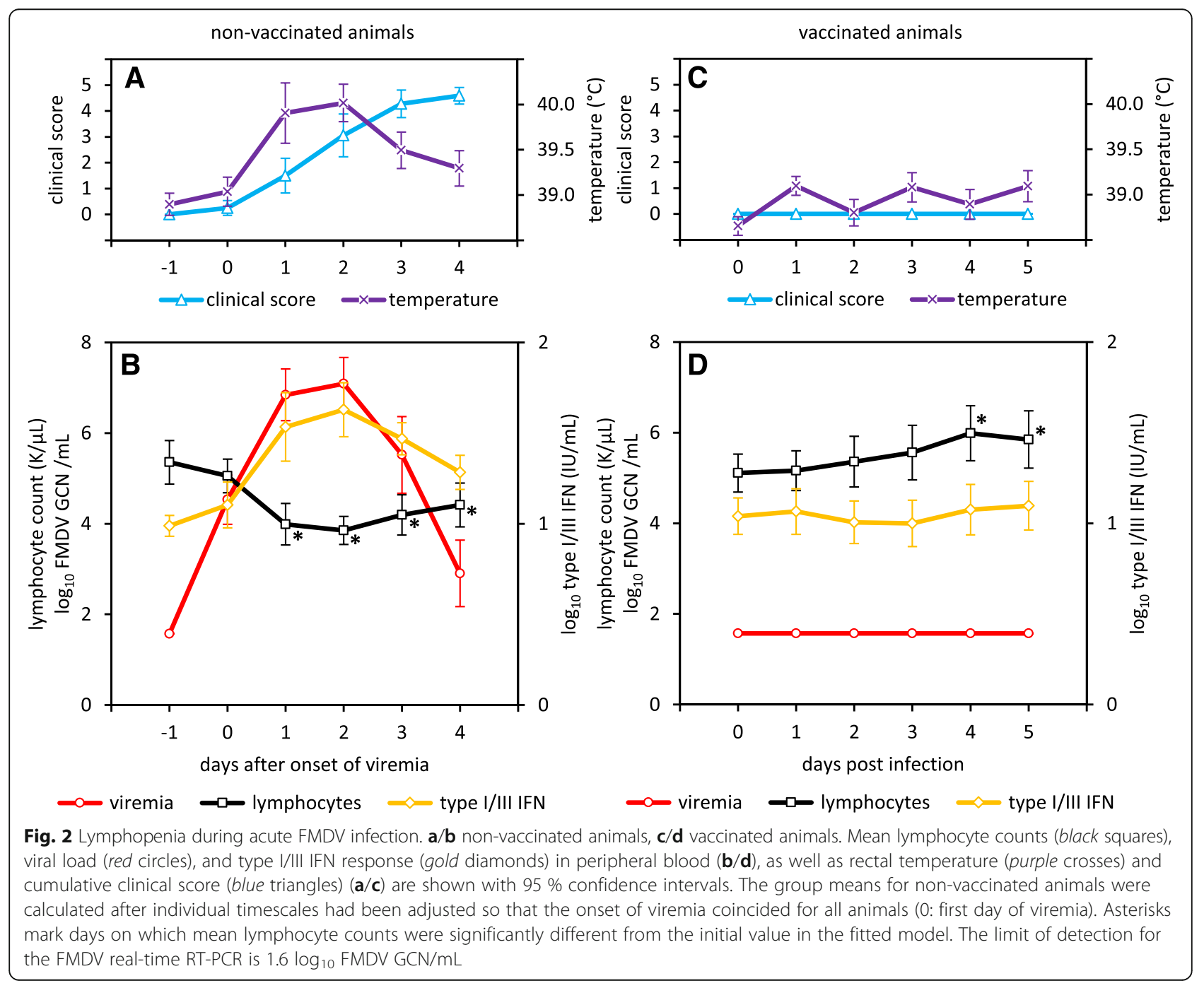


vaccinated animals after challenge (Fig. 2b). The Mx/ CAT assay does not distinguish between type I and type III interferon [20]; hence it was not determined whether the observed interferon response was mediated by type I or type III interferon or both.

\section{Hematology: vaccinated vs. non-vaccinated animals}

No hematological changes were observed after vaccination, and the two groups (vaccinated and non-vaccinated) did not differ in any cell population in the complete blood count prior to challenge (Fig. 3). All further comparisons are made relative to the day of challenge. After challenge, the mean total WBC count decreased in non-vaccinated animals, while it increased in vaccinated animals. Neither change was significant within the groups, but the difference between non-vaccinated animals and vaccinated animals was significant between 4 and $10 \mathrm{dpi}(p<0.05)$ (Fig. 3a). Lymphocyte counts diverged starting at $4 \mathrm{dpi}$, with vaccinated steers having significantly higher counts than non-vaccinated steers $(p<0.05)$ (Fig. 3c). This separation was maintained throughout the early phase of the experiment (until $9 \mathrm{dpi}$ ). Within the vaccinated population, mean lymphocyte counts were significantly increased over pre-challenge levels $(0 \mathrm{dpi})$ on 4 and $5 \mathrm{dpi}$ and again from 7 to 9 dpi $(p<0.05)$. Lymphocyte counts were significantly decreased in non-vaccinated animals from 4 to 8 and on $10 \mathrm{dpi}$ (Fig. 3c). The decrease in circulating lymphocytes closely followed the increase in viremia and type I/III IFN activity in serum detected in this group (Fig. 2). All group means were within established reference ranges for cattle; thus, the changes in lymphocyte quantities are indicative of relative lymphocytosis (in

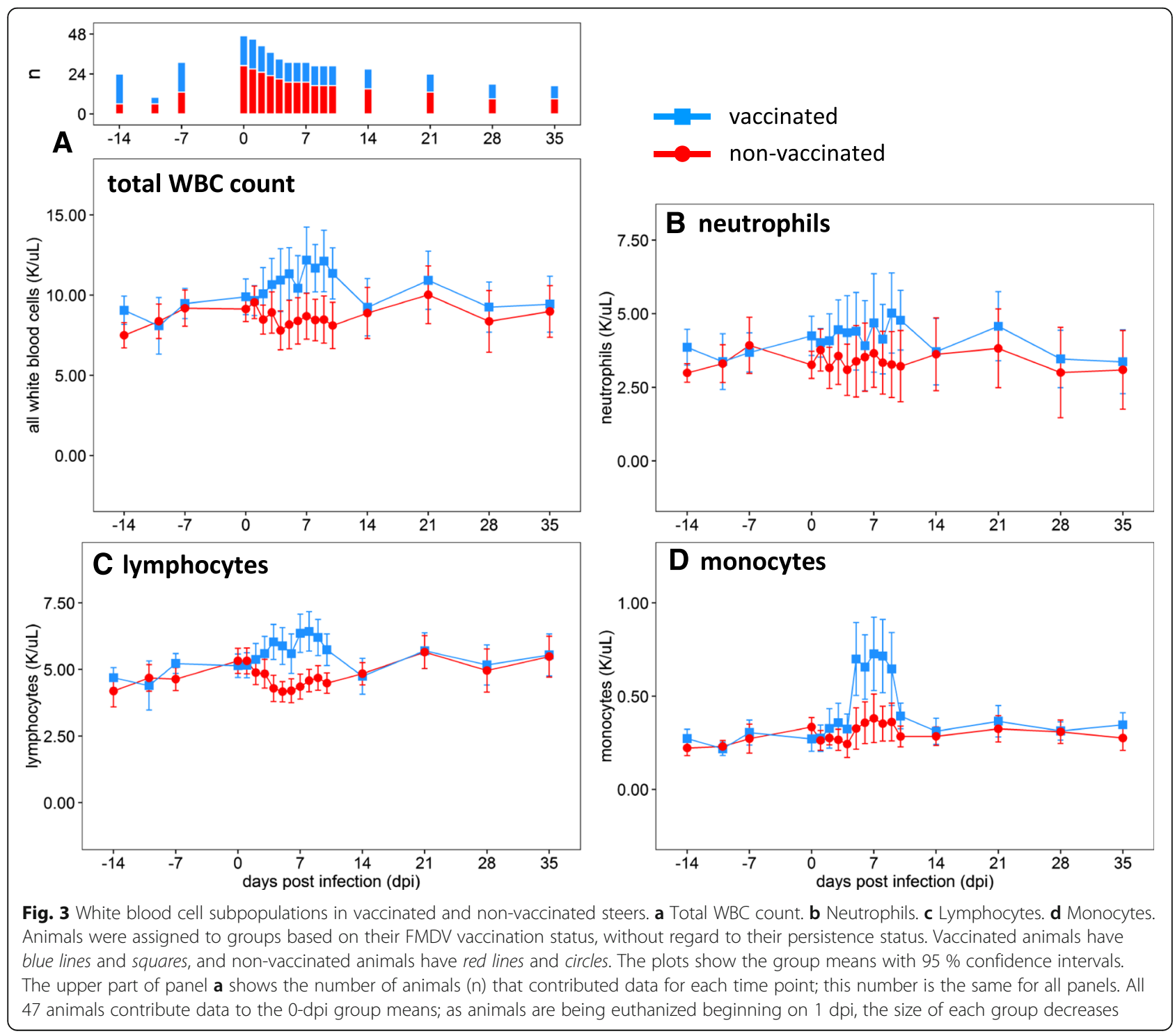


vaccinated animals) and relative lymphopenia (in nonvaccinated animals) after challenge.

Similar to the mean lymphocyte counts, mean monocyte counts varied by vaccination status and time after infection. Mean monocyte counts in non-vaccinated steers were not significantly different over the course of the experiment. Vaccinated steers, however, had relative monocytosis from 5 to 9 dpi $(p<0.05)$ (Fig. 3d). Six individual animals exceeded the threshold for absolute monocytosis at least once, but the group means did not. The three vaccinated animals (out of 18) that lacked definitive evidence of local virus replication did not have increased monocyte counts (not shown).

Mean neutrophil counts did not differ significantly between vaccinated and non-vaccinated steers, nor did they vary significantly over the course of infection (Fig. 3b).

\section{Hematology: FMDV carriers vs. non-carriers}

FMDV persistence status did not correlate with differences in total WBC count or any of its subpopulations. Carrier and non-carrier steers had similar mean hematological parameters over the course of infection (Fig. 4). Non-carrier steers had slightly higher mean lymphocyte counts from 3 to $10 \mathrm{dpi}$, but there was no statistically significant difference $(p>0.05)$. Overall, the observed hematological differences were more substantively associated with vaccination status than with persistence status.

In Fig. 3, animals are assigned to groups based on their FMDV vaccination status, without regard to their persistence status, whereas in Fig. 4, they are assigned to groups based on their FMDV persistence status, without regard to their vaccination status. A set of charts showing the hematology data stratified by vaccination and persistence

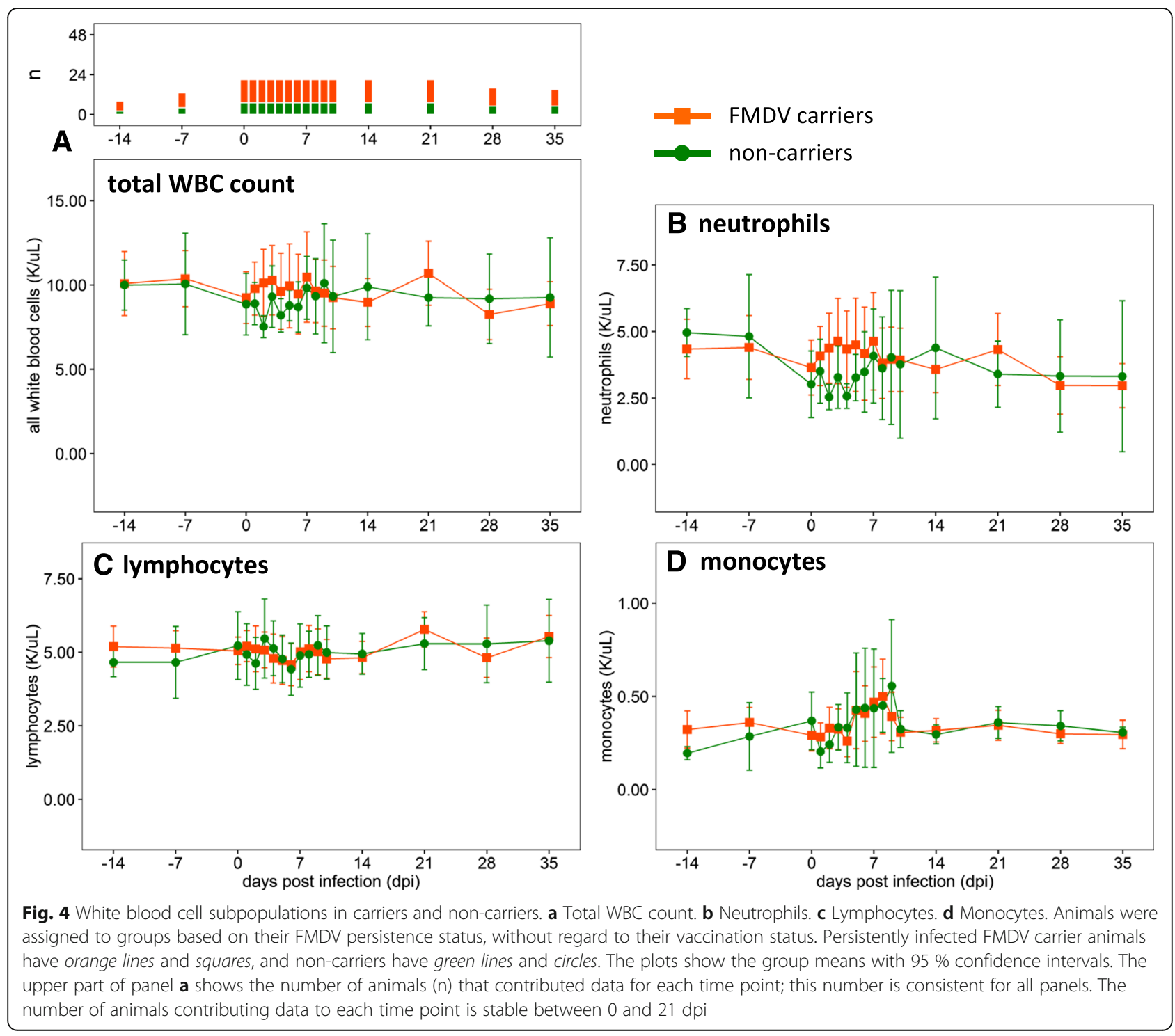


status at the same time is included as Additional file 1: Figure S1 in the online version of this article.

\section{Flow cytometry: Vaccinated vs. non-vaccinated animals} Serial examinations of phenotypic characteristics of PBMCs from forty-seven steers were performed on up to 22 samples per animal by staining in duplicate and evaluating by flow cytometry. The mean coefficent of variation between replicates of the same sample was less than $3 \%$.

The relative size of the $\mathrm{CD}^{+}$population within the morphological lymphocyte gate (forward and side scatter) was variable over time, and trended lower in non-vaccinated animals after challenge. There was a significant difference between vaccinated and non-vaccinated animals on 4 and 5 dpi ( $p<0.05$; not shown).

Based on relative percentage-of-parent values, the $\mathrm{CD} 4^{+}$ and $\mathrm{CD}^{+} \alpha \beta$ T cell subpopulations in vaccinated animals did not change significantly after challenge, but there was a significant increase of $\mathrm{CD}^{+} \alpha \beta \mathrm{T}$ cells and a corresponding decrease of $\mathrm{CD}^{+} \alpha \beta \mathrm{T}$ cells in non-vaccinated animals from 3 to 6 dpi (compared to day $0 ; p<0.05$ for all 4 days, Fig. 5a, b). For each subpopulation, the difference between vaccinated and non-vaccinated animals was significant for the same time period ( 3 to $6 \mathrm{dpi}, p<0.05$ ). The $\mathrm{CD}^{+} / \mathrm{CD}^{+}$ratio in non-vaccinated animals transiently increased from 3.2 at the day of challenge to 4.0 on $5 \mathrm{dpi}$, while it slightly decreased (from 3.3 to 3.1 ) in vaccinated animals.

In order to translate relative population measures obtained by flow cytometry to absolute counts, the percentage-of-parent values from the flow cytometry analysis were applied to the lymphocyte counts obtained with the hematology analyzer. When this conversion was performed, the increase in total circulating lymphocytes (compared to the day of challenge) of up to $25 \%$ in vaccinated animals (Fig. 3c) had greater influence than the relative differences between vaccinated and non-vaccinated animals that have been described above. Thus, absolute quantities of both $\mathrm{CD}^{+}$as well as $\mathrm{CD}^{+} \alpha \beta$ T cells were significantly higher in PBMCs of vaccinated steers than in nonvaccinated steers $(p<0.05)$ from 2 to $10 \mathrm{dpi}$ (Fig. 5c, d).

The absolute decrease (compared to the day of challenge) of the total lymphocyte count in non-vaccinated animals also influenced the counts of the $\mathrm{CD} 4^{+}$and $\mathrm{CD} 8^{+}$ $\alpha \beta \mathrm{T}$ cell subpopulations. In relative terms, $\mathrm{CD}^{+} \alpha \beta \mathrm{T}$ cells had been transiently increased in non-vaccinated
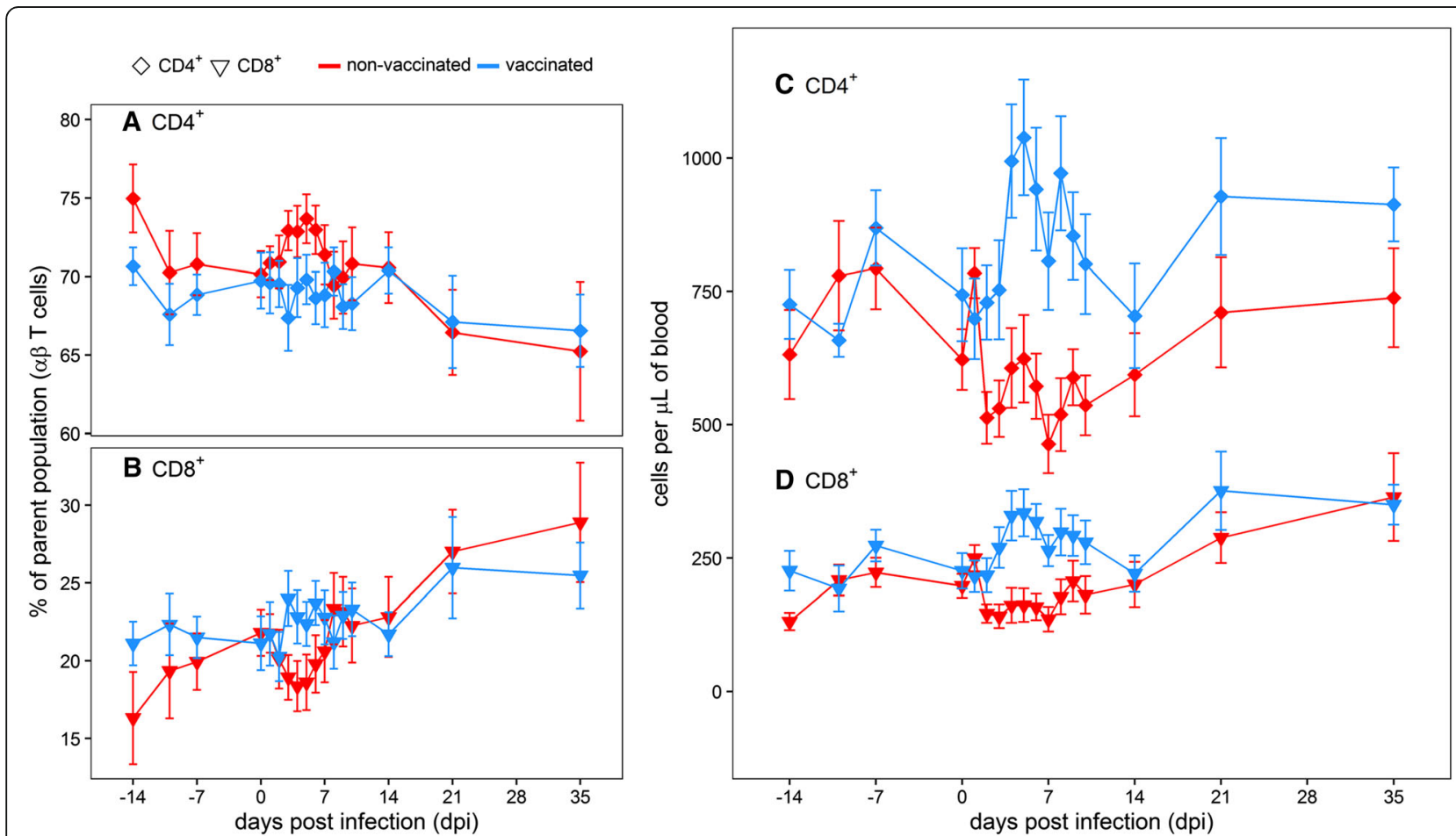

Fig. $5 \mathrm{CD}^{+}$and $C D 8^{+}$a $\beta$ T cells in vaccinated and non-vaccinated animals. Panels $\mathbf{a}$ and $\mathbf{b}$ show percentage values relative to the $C D 3^{+} a \beta T$ cell parent population, and panels $\mathrm{C}$ and $\mathrm{D}$ show absolute cell counts per $\mu \mathrm{L}$ of blood obtained by a dual-platform method. Group means (CD4 ${ }^{+}$: diamonds, $\mathrm{CD}^{+}$: triangles) are annotated with their $95 \%$ confidence intervals, non-vaccinated animals are shown in red and vaccinated animals in blue. Based on relative percentage-of-parent values, there was a significant increase of CD4 $4^{+} \mathrm{\alpha}$ T cells (panel a) and a corresponding decrease of $\mathrm{CD}^{+}$a $\beta$ T cells (b) in non-vaccinated animals. Translated to absolute counts, the increase in total circulating lymphocytes of up to $25 \%$ in vaccinated animals had greater influence than the relative differences between vaccinated and non-vaccinated animals. Thus, absolute quantities of both $\mathrm{CD}^{+}(\mathbf{c})$ as well as $\mathrm{CD} 8^{+}$a $\mathrm{\beta}$ cells $(\mathbf{d})$ were significantly higher in PBMCs of vaccinated steers than in non-vaccinated steers 
animals, while $\mathrm{CD}^{+} \alpha \beta$ T cells had shown a complementary decrease (Fig. 5a, b). The relative increase in $\mathrm{CD} 4^{+}$ cells partially counteracted the total decrease in lymphocytes, whereas the decrease in $\mathrm{CD}^{+}$cells became more pronounced once absolute counts were taken into account (Fig. 5c, d). Absolute $\mathrm{CD}^{+}$cell counts during acute infection fluctuated substantially more than $\mathrm{CD}^{+}$counts (Fig. 5c, d). On day 5 after infection, the day with the largest $\mathrm{CD} 4^{+} / \mathrm{CD}^{+}$ratio (4.0, see above) as well as the nadir of the lymphocyte count in non-vaccinated animals (Fig. 3c), the absolute $\mathrm{CD}^{+}$cell count in nonvaccinated animals was reduced by approximately $20 \%$ compared to day $0(166 \pm 34$ vs. $202 \pm 30$ per $\mu \mathrm{L}$ of blood; means and CI95, $p=0.03$ ), while the absolute $\mathrm{CD} 4{ }^{+}$count was similar to the initial level $(624 \pm 85$ vs. $619 \pm 66, p=0.91)$.

\section{Flow cytometry: FMDV carriers vs. non-carriers}

There were no significant differences between carrier and non-carrier animals in the kinetics of any $\mathrm{T}$ cell population investigated herein, independent of whether vaccinated and non-vaccinated animals were analyzed together or separately, and independent of the measurement scale (relative or absolute).

\section{FMDV-specific humoral immune response}

In vaccinated animals, no FMDV-specific antibodies were detected at $4 \mathrm{dpv}$ (by ELISA only; the 4-dpv sample was not tested in the SNT), but all vaccinated animals had developed FMDV-specific IgM and IgG by $7 \mathrm{dpv}$, and most had detectable neutralizing antibody at the day of challenge (14 dpv; Fig. 6).

All vaccinated animals had detectable FMDV-specific IgM on the day of challenge. Vaccinated animals that went on to become FMDV carriers maintained their prechallenge FMDV IgM levels for the duration of the study, whereas FMDV-specific IgM in vaccinated animals that did not become persistently infected was markedly reduced by $7 \mathrm{dpi}$ (see boxes in Fig. 6a, b). In contrast, FMDV-specific IgM in serum from non-vaccinated animals was first detected on day 5 after challenge. Levels increased quickly over the next few days and peaked on $9 \mathrm{dpi}$. In carriers and non-carriers IgM then declined steadily until the end of the experiment, but remained detectable throughout.

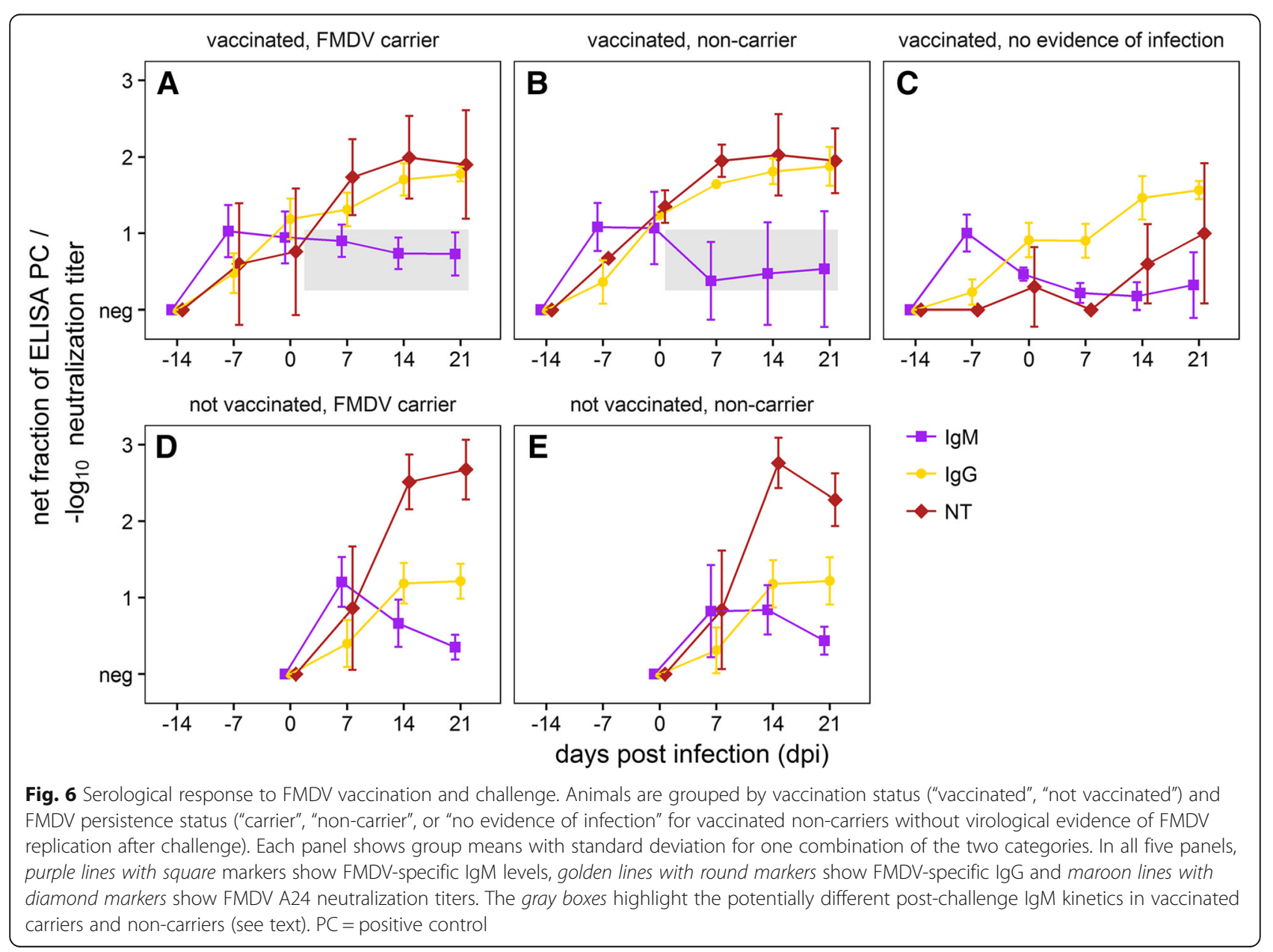


After the first detection on $7 \mathrm{dpv}$, FMDV-specific IgG in vaccinated animals increased steadily until $14 \mathrm{dpi}$. All vaccinated animals had detectable FMDV-specific IgG on the day of challenge. In non-vaccinated animals, specific IgG was first detectable on $6 \mathrm{dpi}$ and rose quickly until 14 dpi. After $14 \mathrm{dpi}$, the levels of specific IgG remained stable in vaccinated and non-vaccinated animals, but the final levels in vaccinated animals were higher than in non-vaccinated animals (Fig. 6a, b).

Neutralizing antibody levels in vaccinated and nonvaccinated animals generally correlated with FMDVspecific IgG rather than with IgM. However, in contrast to the ELISA data, final levels of neutralizing antibodies were higher in animals that had not been vaccinated before challenge and thus had developed fulminant FMD (Fig. 6d, e). The three vaccinated animals without virological evidence of local FMDV replication or dissemination had lower specific antibody levels than other vaccinated animals, both before and after challenge (Fig. 6c); however they did have increases in IgG and neutralization titers after challenge.

Apart from the slightly different IgM kinetics in vaccinated animals after challenge, there was no difference in FMDV-specific circulating antibody between carriers and non-carriers.

\section{Isotype-specific characterization of anti-FMDV B cells}

FMDV-specific circulating $B$ cells of six non-vaccinated animals were evaluated using an antibody ELISPOT assay. Anti-FMDV antibody-secreting cells were first detected in non-vaccinated animals on 5 dpi. IgM-secreting cells peaked between 7 and $14 \mathrm{dpi}$, and had disappeared from peripheral blood by $14 \mathrm{dpi}$. IgG-secreting cell counts in circulation increased until $14 \mathrm{dpi}$, and then declined. Low levels of FMDV IgG-secreting cells remained detectable in peripheral blood until the end of the experiment (Fig. 7).

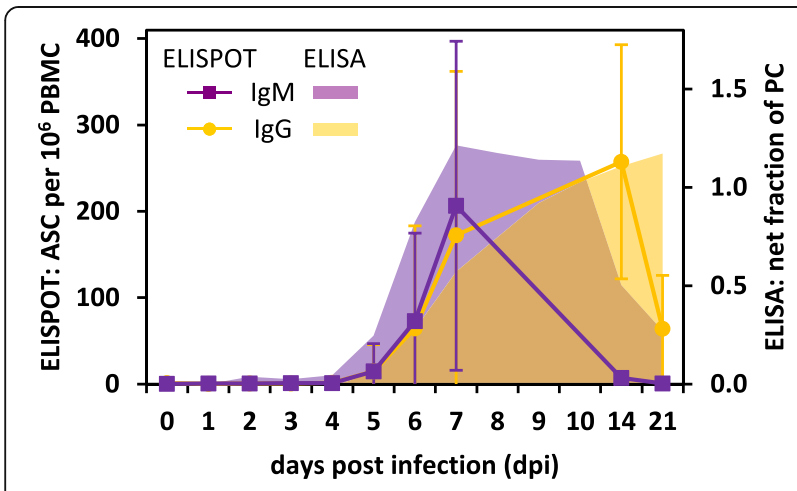

Fig. 7 FMDV-specific humoral immune response in 6 non-vaccinated animals. Antibody-secreting cells (ASC) in peripheral blood were counted with ELISPOT assays, and circulating antibody was measured by sandwich ELISAs. IgM is shown in purple, IgG in gold. Error bars show sample standard deviation. PC = positive control

\section{Discussion}

The present study examined the systemic response to FMDV infection in cohorts of non-vaccinated and vaccinated cattle with the purpose of investigating systemic immune system factors that may correlate with the divergence between FMDV carriers and non-carriers. Persistent infection can follow either a clinical or a subclinical FMDV infection and generally occurs at the same rate regardless of vaccination reviewed in [67]. The protective efficacy of Ad5-FMDV vaccination against disseminated disease has been demonstrated previously $[46,68,69]$, but the incidence and characteristics of persistent infection after challenge of Ad5-FMDV-vaccinated cattle was studied here for the first time. Complete blood counts, $\mathrm{T}$ lymphocyte subpopulations, type I/III IFN response, as well as FMDV-specific antibody production and activity were compared between vaccinated and nonvaccinated animals and between carriers and non-carriers at an unprecedented level of detail. Before challenge, vaccinated cattle had detectable humoral immunity against FMDV. After challenge, all non-vaccinated steers became viremic and developed clinical disease, while the vaccinated steers did not. This divergence coincided with distinctive differences in several parameters. On the other hand, only slight differences were identified between animals that went on to become FMDV carriers compared to those which cleared the infection.

The present study confirmed earlier findings that summary WBC levels in non-vaccinated animals remain within the clinical reference range during acute FMDV infection and do not change significantly from the outset [28]. There was, however, a significant change in lymphocyte levels, which transiently decreased in non-vaccinated animals after FMDV challenge. This relative lymphopenia was significant compared to pre-infection levels; however, the animals were never lymphopenic relative to the established clinical reference range [56], which underscores the utility of reference change values over population-level standards in animal research [70].

Lymphopenia is a common feature of acute viral infections [71]. It is a well-described phenomenon in FMDVinfected pigs [24, 25, 72], and has previously been reported in FMDV-infected cattle in at least two studies $[20,26]$. There are several mechanisms by which viruses can cause lymphopenia. Lymphocytes may be redistributed from the blood into infected tissues, e.g. through the action of type I IFNs. Alternatively, apoptosis of lymphocytes can be a direct result of viral infection or caused indirectly through cytokine induction [73]. In the present study, the decrease in circulating lymphocytes closely followed the increase in systemic type I/III IFN activity, which in turn was highly correlated with FMDV viremia. Thus, these findings are consistent with the observed lymphopenia being due to IFN-induced lymphocyte migration 
from the blood to sites of infection or lymphoid tissues [74]. The CBC only examines circulating cells; animals with a relative lymphopenia may have normal or even increased levels of total body lymphocytes and the reduction in circulating lymphocytes alone does not necessarily represent a decline in immune competence. It has been argued that transient virus-induced and IFN-mediated lymphopenia is, in fact, a physiological response and beneficial to the host reviewed in [74].

Similarly, increased lymphocyte counts, as were detected in the vaccinated animals in the present study, are often seen after antigenic stimulation [71]. The recall response after challenge of vaccinated animals is the result of an increased quantity of primed antigen-specific B and $\mathrm{T}$ cells, which can expand more quickly. Memory cells are activated more readily than naïve cells and can respond to lower doses of antigen [75].

As the bridge between innate and adaptive immunity, monocytes and macrophages are a key component in antigen presentation, phagocytosis, and viral clearance [76]. They usually form only a small part of the circulating leukocyte pool. In the present study, monocyte numbers did not change significantly after vaccination, or after FMDV infection of non-vaccinated animals, but there was a striking pattern in vaccinated steers after challenge. Four days after challenge, and two days after circulating lymphocyte counts had started to increase, monocyte counts rose sharply and remained high (approximately $50 \%$ above baseline) for several days. Sigal et al. [77] have previously reported a similar increase of monocytes in FMDV-vaccinated animals 1 week after challenge.

Monocytes are released into circulation from the bone marrow and spleen in response to inflammation signals [78], and move quickly to sites of infection where they differentiate into macrophages or dendritic cells. Increased antigen presentation and lymphocyte activation stimulate additional monocyte recruitment through positive feedback loops [79]. Opsonization by specific antibody and phagocytosis are major factors in the immune defense against FMDV [80, 81]. Additionally, pDC activation by FMDV is also substantially enhanced in the presence of FMDV-specific antibodies [82]. In the vaccinated animals, protection from FMD occurred in the presence of abundant anti-FMDV immunoglobulin combined with elevated circulating monocyte counts, both of which were likely contributors to the effective immune response.

It has previously been shown that there is a strong systemic type I/III IFN response during acute FMDV infection of cattle [19, 21, 22], and this was again confirmed in the large cohort of unvaccinated cattle in the present study. High IFN activity is also detectable in tissues of FMDV-infected animals, but it is restricted to sites of virus replication [22]. It is unclear how much of the locally produced IFN enters the vasculature, and it has been suggested that the circulating type I/III IFN is instead produced by $\mathrm{CD} 4^{+}$pDCs interacting with immunecomplexed virus [18]. A flow cytometric analysis of ex vivo interferon production in pDCs from the FMDV-infected animals would have provided useful information in this regard, but this was beyond the scope of the present study.

No infectious virus or FMDV RNA was detected in serum of vaccinated animals in the present study; thus, the lack of a systemic type I/III IFN response could be explained by the absence of the crucial stimulus for its production. However, induction of transcription of IFN genes and IFN bioactivity was detected in pharyngeal tissues of vaccinated cattle from this study [38].

In addition to its critical role in innate immunity, type I IFN can act directly on both $\mathrm{CD} 4^{+}$and $\mathrm{CD} 8^{+} \mathrm{T}$ cells, positively or negatively influencing their function reviewed in [83]. T cells are the dominant lymphocyte population in peripheral blood of cattle [84]. For the first time, the present study identified significant changes in $\alpha \beta$ T cells in non-vaccinated steers challenged with FMDV, complementing earlier work on $\gamma \delta$ T cells [85]. After infection, non-vaccinated animals had a significant decrease in the relative quantity of $\mathrm{CD}^{+} \alpha \beta$ T cells for several days, while the same cell population in vaccinated animals remained stable. Conversely, the relative $\mathrm{CD} 4^{+} \alpha \beta \mathrm{T}$ cell population in non-vaccinated animals was larger during that time, but did not change in vaccinated animals. In order to determine which subset was responsible for the change in the $\mathrm{CD}^{+} / \mathrm{CD}^{+}$ratio, lymphocyte counts from the $\mathrm{CBC}$ were applied to the relative changes of lymphocyte subpopulations - commonly referred to as the dual-platform method of obtaining absolute counts [60]. The multicolor staining panel used in the present study also accounts for non-T lymphocytes and $\gamma \delta$ T cells. Using this method, absolute $\mathrm{CD} 4^{+}$counts in non-vaccinated animals were found to be stable during acute infection, while the absolute $\mathrm{CD}^{+}$counts were significantly decreased. This indicates selective depletion (or redistribution) of circulating $\mathrm{CD} 8^{+}$ $\alpha \beta \mathrm{T}$ lymphocytes in FMDV-infected non-vaccinated cattle. A similar pattern has been previously described in swine [24, 25], compounded by evidence of functional impairment (e.g., mitogen unresponsiveness) of the residual circulating $\mathrm{T}$ cell population. A variety of explanations for these observations have been suggested [74], including FMDV infection of $\mathrm{T}$ lymphocytes or T-cell suppression by IL-10 overproduction [86]. Joshi et al. [87] reported a similarly inhibited response to mitogen in FMDV-infected bovine lymphocytes, but other studies found no evidence of changes in $\mathrm{CD} 4^{+}$and $\mathrm{CD} 8^{+}$populations, T-cell impairment or increased circulating IL-10 during acute FMDV infection in small cohorts of cattle [27, 28].

The time course of the FMDV-specific antibody response observed in the present study was similar to previously 
published results from other groups [27, 88-90]. Direct comparisons of the magnitude of the response, however, are impossible because of differences in the test format (endpoint dilution vs. optical density at a fixed dilution, use of monoclonal anti-isotype vs. polyclonal anti-isotype antibodies, etc.). In addition, neither system allows for a fully quantitative comparison of different immunoglobulin isotypes within a sample, only of relative levels of the same isotype between samples [89].

When comparing the antibody development after challenge between FMDV-vaccinated and non-vaccinated animals, Mulcahy et al. [89] saw a transient increase of specific IgM in non-vaccinated animals, followed by a sustained increase of specific IgG. This is the classical pattern of a primary immune response [91] that was also seen in non-vaccinated animals in the present study. Similar to what has been discussed for cellular adaptive responses, secondary or recall antibody responses differ from primary responses. They occur more rapidly, they consist of relatively more IgG than IgM, and they are of higher affinity [75]. Indeed, no rise in specific IgM was seen after challenge in the vaccinated animals in the present study, but FMDV-specific IgG levels in vaccinated animals did increase after challenge.

This increase was also seen in the three vaccinated animals that lacked evidence of local virus replication, possibly because antibody-bound FMDV was recognized by the immune system and induced an anamnestic response. Alternatively, there could have been low-level replication that was not directly detectable and which was insufficient to induce measurable antibodies against non-structural proteins. Overall, the data support these animals not having been infected. Strikingly, they only had low neutralizing antibody titers and no detectable type I/III interferon in serum before challenge; thus, the specific mechanisms that facilitated their apparent sterile protection remains undetermined. While the neutralizing antibody profiles between serum and nasal fluid of FMDV-vaccinated pigs are similar, this is not necessarily true for cattle [92], and the low serum titers are not indicative of a similarly low mucosal response.

Persisting serum IgM is used to diagnose chronic viral infections such as hepatitis B and C in humans. Contrary to the results presented here, Salt et al. [90] had not seen such a pattern for FMDV-specific IgM in carriers. In the present study, modestly elevated FMDV-specific IgM was detected in carriers. This may be because persistent FMDV infection is not highly productive, unlike the aforementioned chronic infections. It is interesting to note, too, that while IgM remains detectable, IgM-secreting cells disappear from circulation, possibly indicating a more localized production of the antibodies-similar to what has been described for the IgA response to persistent infection [42]. The magnitude of the difference in IgM kinetics between carriers and non-carriers, however, appears to be too small to be of diagnostic utility. As has been reported previously reviewed in [4], no component of the serum antibody response in the present study was significantly different between carriers and non-carriers.

\section{Conclusions}

This study corroborates the notion that vaccination and prevention of clinical disease offer no protection against either primary or persistent FMDV infection [12, 38, 90]. This is the first use of high-resolution hematology and multi-color flow cytometry data from a large cohort of animals, all exposed to the virus under simulated-natural conditions and closely monitored for the full course of infection. Lymphopenia and selective CTL depletion were found to be significant phenomena during the acute infection of naïve cattle, in contrast with a robust cellular immune response in vaccinated animals. However, none of the systemic parameters examined-type I/III interferon, FMDV-specific antibodies, circulating leukocyte populations and T-lymphocyte subsets-were associated with the FMDV carrier state divergence, emphasizing the highly localized nature of persistent FMDV infection. This suggests that tissue-level studies of sites of persistence may be required to elucidate the mechanisms associated with establishment and resolution of persistent FMD, and such studies are currently underway in our laboratory.

\section{Additional files}

\begin{abstract}
Additional file 1: Figure S1. White blood cell subpopulations by vaccination and persistence status. A: Total WBC count. B: Neutrophils. C: Lymphocytes. D: Monocytes. Animals were assigned to one of four groups based on their FMDV vaccination and persistence status. Group means are shown with $95 \%$ confidence intervals. Means are marked with orange circles for carrier animals and green circles for non-carriers; individual time points are connected with blue lines for vaccinated animals and with red lines for non-vaccinated animals. Small numbers at the bottom of each panel state the number of animals that contributed data to each time point. (PDF $595 \mathrm{~kb}$ )
\end{abstract}

Additional file 2: Table S1. Full dataset in tab-separated format. (TSV 70 kb)

\section{Abbreviations}

ANOVA: Analysis of variance; ARS: Agricultural Research Service; BB: Blocking buffer; CAT: Chloramphenicol acetyltransferase; CBC: Complete blood count; CD: Cluster of differentiation; C195: 95 \% confidence interval; $\mathrm{CO}_{2}$ : Carbon dioxide; $C_{t}$ : Cycle threshold; CTL: Cytotoxic T lymphocyte(s); Dpi: Days postinfection; Dpv: Days post-vaccination; ELISA: Enzyme-linked immunosorbent assay; ELISPOT: Enzyme-linked immunospot; FACS: Fluorescence-activated cell sorting; FADRU: Foreign Animal Disease Research Unit; FBS: Fetal bovine serum; FMD: Foot-and-mouth disease; FMDV: Foot-and-mouth disease virus; GCN: Genome copy number; HEPES: 4-(2-hydroxyethyl)-1piperazineethanesulfonic acid; HRP: Horseradish peroxidase; IFN: Interferon; IgG: Immunoglobulin gamma; IgM: Immunoglobulin mu; IL-10: Interleukin 10; INP: Intranasopharyngeal; $K_{2}$ EDTA: Dipotassium ethylenediaminetetraacetic acid; LFBK: Lois' and Fran's bovine kidney cells; MEM: Minimum essential medium; Mx: Mx1, Myxovirus resistance protein 1; nFPC: Fraction of the net OD of the positive control; NSP: Non-structural protein; OD: Optical density; OPF: Oropharyngeal fluid(s); ORISE: Oak Ridge Institute for Science and Education; PBMC: Peripheral-blood mononuclear cell(s); PBS: Phosphate- 
buffered saline; PBST: Phosphate-buffered saline with TWEEN(R); PC: Positive control; pDC: Plasmacytoid dendritic cell; PIADC: Plum island animal disease center; RNA: Ribonucleic acid; RPMI: Roswell park memorial institute; RT-PCR: Reverse transcription polymerase chain reaction; SNT: serum neutralization test; $\mathrm{TCID}_{50}$ : 50 \% tissue culture infective doses; TTE: 1,1,2trichlorofluoroethane; USDA: United States Department of Agriculture; WBC: White blood cell(s)

\section{Acknowledgments}

Elizabeth Rieder and Michael LaRocco provided anti-NSP ELISA data for a subset of animal samples. The authors thank the Animal Resource Branch at PIADC for assistance with animal procedures.

This work is dedicated to the memory of Bernd Haas.

\section{Funding}

This work was funded in part by CRIS project 1940-32000-057-00D (USDA, Agricultural Research Service), as well as through an interagency agreement with the Science and Technology Directorate of the U.S. Department of Homeland Security under Award Number HSHQPM-13-X-00131. ME, CS, and SIR are recipients of PIADC Research Participation Program fellowships, administered by the Oak Ridge Institute for Science and Education (ORISE) through an interagency agreement with the U.S. Department of Energy. The sponsors had no involvement in the study design, in the collection, analysis and interpretation of data, in the writing of the manuscript, or in the decision to submit the manuscript for publication.

\section{Availability of data and material}

The dataset supporting the conclusions of this article is provided as Additional file 2: Table S1.

\section{Authors' contributions}

ME carried out the flow cytometry assays and the statistical analysis, participated in the development of the flow cytometry assays, in the animal experiments, sample processing and data analysis, the interferon bioassay, hematology, neutralization tests, and the ELISPOT, and wrote and revised the manuscript. CS coordinated and carried out the animal experiments, participated in the sample processing, data analysis and the conception, design, and coordination of the study, and co-wrote the manuscript. SIR carried out the antibody ELISA and hematology, and participated in the interferon bioassay, animal experiments, sample processing, data analysis and the editing of the manuscript. JMP developed the antibody ELISA, adapted the neutralization test, and participated in the coordination of the animal experiments, the conception, design and coordination of the study, data analysis and the revision of the manuscript. EJH and GRS participated in the sample processing, and carried out the virus isolation, real-time RT-PCR and the neutralization test. MAK performed the ELISPOT, and participated in the sample processing, the development of the ELISPOT and the flow cytometry assays and the data analysis. WTG participated in the development of the ELISPOT and flow cytometry assays, the data analysis, study design and coordination, and the revision of the manuscript. LLR participated in the conception and the design of the study and reviewed the manuscript. JA conceived, designed and coordinated the study, co-wrote the manuscript, and coordinated and participated in the animal experiments. All authors read and approved the final manuscript.

\section{Competing interests}

The authors declare that they have no competing interests. Mention of trade names or commercial products in this article is solely for the purpose of providing specific information and does not imply recommendation or endorsement by the USDA. The content is solely the responsibility of the authors and does not necessarily represent the official views of the USDA or any other U.S. federal entity.

\section{Consent for publication}

Not applicable.

\section{Ethics approval and consent to participate}

All animal procedures were performed at the Plum Island Animal Disease Center (PIADC) under experimental protocols approved by the PIADC Institutional Animal Care and Use Committee (protocol numbers 209-12-R, 209-15-R).

\section{Author details}

'United States Department of Agriculture (USDA), Plum Island Animal Disease Center (PIADC), Foreign Animal Disease Research Unit (FADRU), Agricultural Research Service (ARS), P.O. Box 848, Greenport, NY 11944, USA. ${ }^{2}$ Oak Ridge Institute for Science and Education, PIADC Research Participation Program, Oak Ridge, TN, USA.

Received: 5 January 2016 Accepted: 10 September 2016

Published online: 15 September 2016

\section{References}

1. Grubman MJ, Baxt B. Foot-and-mouth disease. Clin Microbiol Rev. 2004;17(2):465-93.

2. Arzt J, Juleff N, Zhang Z, Rodriguez LL. The pathogenesis of foot-and-mouth disease I: viral pathways in cattle. Transbound Emerg Dis. 2011;58(4):291-304.

3. Alexandersen S, Zhang Z, Donaldson Al, Garland AJM. The pathogenesis and diagnosis of foot-and-mouth disease. J Comp Pathol. 2003;129(1):1-36.

4. Alexandersen S, Zhang Z, Donaldson Al. Aspects of the persistence of foot-and-mouth disease virus in animals-the carrier problem. Microbes Infect. 2002;4(10):1099-110.

5. Salt JS. The carrier state in foot and mouth disease-an immunological review. Br Vet J. 1993;149(3):207-23.

6. OIE. Foot-and-Mouth Disease. In: Manual of Diagnostic Tests and Vaccines for Terrestrial Animals. 7th ed. 2012. p. 163.

7. Stenfeldt C, Belsham GJ. Detection of foot-and-mouth disease virus RNA in pharyngeal epithelium biopsy samples obtained from infected cattle: investigation of possible sites of virus replication and persistence. Vet Microbiol. 2012;154(3-4):230-9.

8. Zhang ZD, Kitching RP. The localization of persistent foot and mouth disease virus in the epithelial cells of the soft palate and pharynx. J Comp Pathol. 2001;124(2-3):89-94.

9. Burrows R. Studies on the carrier state of cattle exposed to foot-and-mouth disease virus. J Hyg (Lond). 1966;64(1):81-90.

10. Pacheco JM, Smoliga GR, O'Donnell V, Brito BP, Stenfeldt C, Rodriguez LL, Arzt J. Persistent Foot-and-Mouth Disease Virus Infection in the Nasopharynx of Cattle; Tissue-Specific Distribution and Local Cytokine Expression. PLoS ONE. 2015;10(5), e0125698.

11. Prato Murphy ML, Forsyth MA, Belsham GJ, Salt JS. Localization of foot-andmouth disease virus RNA by in situ hybridization within bovine tissues. Virus Res. 1999;62(1):67-76.

12. Stenfeldt C, Eschbaumer M, Rekant SI, Pacheco J, Smoliga G, Hartwig E, Rodriguez L, Arzt J. The foot-and-mouth disease carrier state divergence in cattle. J Virol. 2016. in press.

13. Juleff N, Windsor M, Reid E, Seago J, Zhang Z, Monaghan P, Morrison IW, Charleston B. Foot-and-mouth disease virus persists in the light zone of germinal centres. PLoS ONE. 2008;3(10), e3434.

14. Zhang ZD, Hutching G, Kitching P, Alexandersen S. The effects of gamma interferon on replication of foot-and-mouth disease virus in persistently infected bovine cells. Arch Virol. 2002;147(11):2157-67.

15. Reid $\mathrm{E}$, Charleston B. Type I and III interferon production in response to RNA viruses. J Interferon Cytokine Res. 2014;34(9):649-58.

16. Sommereyns C, Paul S, Staeheli P, Michiels T. IFN-lambda (IFN-lambda) is expressed in a tissue-dependent fashion and primarily acts on epithelial cells in vivo. PLoS Pathog. 2008;4(3), e1000017.

17. Fray MD, Mann GE, Charleston B. Validation of an Mx/CAT reporter gene assay for the quantification of bovine type-I interferon. J Immunol Methods. 2001;249(1-2):235-44.

18. Reid E, Juleff N, Gubbins S, Prentice H, Seago J, Charleston B. Bovine plasmacytoid dendritic cells are the major source of type I interferon in response to foot-and-mouth disease virus in vitro and in vivo. J Virol. 2011;85(9):4297-308.

19. Howey R, Bankowski B, Juleff N, Savill NJ, Gibson D, Fazakerley J, Charleston $B$, Woolhouse ME. Modelling the within-host dynamics of the foot-andmouth disease virus in cattle. Epidemics. 2012;4(2):93-103.

20. Perez-Martin E, Weiss M, Diaz-San Segundo F, Pacheco JM, Arzt J, Grubman MJ, Delos Santos T. Bovine type III interferon significantly delays and reduces the severity of foot-and-mouth disease in cattle. J Virol. 2012;86(8):4477-87.

21. Stenfeldt C, Heegaard PM, Stockmarr A, Tjørnehøj K, Belsham GJ. Analysis of the acute phase responses of Serum Amyloid A, Haptoglobin and Type 1 Interferon in cattle experimentally infected with foot-and-mouth disease virus serotype O. Vet Res. 2011;42:66. 
22. Arzt J, Pacheco JM, Smoliga GR, Tucker MT, Bishop E, Pauszek SJ, Hartwig EJ, Delos Santos T, Rodriguez LL. Foot-and-mouth disease virus virulence in cattle is co-determined by viral replication dynamics and route of infection. Virology. 2014;452-453:12-22.

23. Sei JJ, Ochoa AS, Bishop E, Barlow JW, Golde WT. Phenotypic, ultra-structural, and functional characterization of bovine peripheral blood dendritic cell subsets. PLoS ONE. 2014;9(10), e109273.

24. Bautista EM, Ferman GS, Golde WT. Induction of lymphopenia and inhibition of $T$ cell function during acute infection of swine with foot and mouth disease virus (FMDV). Vet Immunol Immunopathol. 2003;92(1-2):61-73.

25. Diaz-San Segundo F, Salguero FJ, De Avila A, De Marco MM, Sanchez-Martin MA Sevilla N. Selective lymphocyte depletion during the early stage of the immune response to foot-and-mouth disease virus infection in swine. J Virol. 2006;80(5):2369-79.

26. Maddur MS, Gajendragad MR, Gopalakrishna S, Singh N. Comparative study of experimental Foot-and-Mouth Disease in cattle (Bos indicus) and buffaloes (Bubalis bubalus). Vet Res Commun. 2008;32(6):481-9.

27. Juleff N, Windsor M, Lefevre EA, Gubbins S, Hamblin P, Reid E, McLaughlin K, Beverley PC, Morrison IW, Charleston B. Foot-and-mouth disease virus can induce a specific and rapid CD4+ T-cell-independent neutralizing and isotype class-switched antibody response in naive cattle. J Virol. 2009;83(8):3626-36.

28. Windsor MA, Carr BV, Bankowski B, Gibson D, Reid E, Hamblin P, Gubbins S, Juleff N, Charleston B. Cattle remain immunocompetent during the acute phase of foot-and-mouth disease virus infection. Vet Res. 2011;42:108.

29. Carr BV, Lefevre EA, Windsor MA, Inghese C, Gubbins S, Prentice H, Juleff ND, Charleston B. CD4+ T-cell responses to foot-and-mouth disease virus in vaccinated cattle. J Gen Virol. 2013;94(Pt 1):97-107.

30. Pega J, Bucafusco D, Di Giacomo S, Schammas JM, Malacari D, Capozzo AV, Arzt J, Pérez-Beascoechea C, Maradei E, Rodríguez LL, et al. Early adaptive immune responses in the respiratory tract of foot-and-mouth disease virus-infected cattle. J Virol. 2013;87(5):2489-95.

31. Patch JR, Pedersen LE, Toka FN, Moraes M, Grubman MJ, Nielsen M, Jungersen G, Buus S, Golde WT. Induction of foot-and-mouth disease virus-specific cytotoxic T cell killing by vaccination. Clin Vaccine Immunol. 2011;18(2):280-8.

32. Patch JR, Kenney M, Pacheco JM, Grubman MJ, Golde WT. Characterization of cytotoxic T lymphocyte function after foot-and-mouth disease virus infection and vaccination. Viral Immunol. 2013;26(4):239-49.

33. Cox SJ, Voyce C, Parida S, Reid SM, Hamblin PA, Paton DJ, Barnett PV. Protection against direct-contact challenge following emergency FMD vaccination of cattle and the effect on virus excretion from the oropharynx. Vaccine. 2005;23(9):1106-13.

34. McVicar JW, Sutmoller P. Growth of foot-and-mouth disease virus in the upper respiratory tract of non-immunized, vaccinated, and recovered cattle after intranasal inoculation. J Hyg (Lond). 1976;76(3):467-81.

35. Aggarwal N, Zhang Z, Cox S, Statham R, Alexandersen S, Kitching RP, Barnett PV. Experimental studies with foot-and-mouth disease virus, strain O, responsible for the 2001 epidemic in the United Kingdom. Vaccine. 2002;20(19-20):2508-15.

36. Cox SJ, Voyce C, Parida S, Reid SM, Hamblin PA, Hutchings G, Paton DJ, Barnett PV. Effect of emergency FMD vaccine antigen payload on protection, sub-clinical infection and persistence following direct contact challenge of cattle. Vaccine. 2006;24(16):3184-90.

37. Golde WT, Pacheco JM, Duque H, Doel T, Penfold B, Ferman GS, Gregg DR, Rodriguez LL. Vaccination against foot-and-mouth disease virus confers complete clinical protection in 7 days and partial protection in 4 days: Use in emergency outbreak response. Vaccine. 2005;23(50):5775-82.

38. Stenfeldt C, Eschbaumer M, Pacheco JM, Rekant SI, Rodriguez LL, Arzt J. Pathogenesis of Primary Foot-and-Mouth Disease Virus Infection in the Nasopharynx of Vaccinated and Non-Vaccinated Cattle. PLOS ONE. 2015;10(11), e0143666.

39. Doel TR, Williams L, Barnett PV. Emergency vaccination against foot-andmouth disease: rate of development of immunity and its implications for the carrier state. Vaccine. 1994;12(7):592-600.

40. Hedger RS. Observations on the carrier state and related antibody titres during an outbreak of foot-and-mouth disease. J Hyg (Lond). 1970;68(1):53-60.

41. Parida S, Cox SJ, Reid SM, Hamblin P, Barnett PV, Inoue T, Anderson J, Paton DJ. The application of new techniques to the improved detection of persistently infected cattle after vaccination and contact exposure to foot-and-mouth disease. Vaccine. 2005;23(44):5186-95.
42. Parida S, Anderson J, Cox SJ, Barnett PV, Paton DJ. Secretory IgA as an indicator of oro-pharyngeal foot-and-mouth disease virus replication and as a tool for post vaccination surveillance. Vaccine. 2006;24(8):1107-16.

43. Maddur MS, Gajendragad MR, Kishore S, Chockalingam AK, Suryanarayana W, Gopalakrishna S, Singh N. Enhanced mucosal immune response in cattle persistently infected with foot-and-mouth disease virus. Vet Immunol Immunopathol. 2008;125(3-4):337-43.

44. McCullough KC, Bruckner L, Schaffner R, Fraefel W, Muller HK, Kihm U. Relationship between the anti-FMD virus antibody reaction as measured by different assays, and protection in vivo against challenge infection. Vet Microbiol. 1992;30(2-3):99-112.

45. Robiolo B, La Torre J, Maradei E, Beascoechea CP, Perez A, Seki C, Smitsaart E, Fondevila N, Palma E, Goris N, et al. Confidence in indirect assessment of footand-mouth disease vaccine potency and vaccine matching carried out by liquid phase ELISA and virus neutralization tests. Vaccine. 2010;28(38):6235-41.

46. Brake DA, Mcllhaney M, Miller T, Christianson K, Keene A, Lohnas G, Purcell C, Neilan J, Schutta C, Barrera J, et al. Human adenovirus-vectored foot-andmouth disease vaccines: establishment of a vaccine product profile through in vitro testing. Dev Biol (Basel). 2012;134:123-33.

47. Rieder E, Henry T, Duque $H$, Baxt B. Analysis of a foot-and-mouth disease virus type A24 isolate containing an SGD receptor recognition site in vitro and its pathogenesis in cattle. J Virol. 2005;79(20):12989-98.

48. Stenfeldt C, Pacheco JM, Singanallur NB, Ferreira HC, Vosloo W, Rodriguez LL, Arzt J. Clinical and virological dynamics of a serotype O 2010 South East Asia lineage foot-and-mouth disease virus in sheep using natural and simulated natural inoculation and exposure systems. Vet Microbiol. 2015;178:50-60.

49. Sutmoller P, Gaggero A. Foot-and mouth diseases carriers. Vet Rec. 1965:77(33):968-9.

50. Sutmoller P, Cottral GE. Improved techniques for the detection of foot-andmouth disease virus in carrier cattle. Arch Gesamte Virusforsch. 1967;21(2):170-7.

51. Eschbaumer M, Stenfeldt C, Pacheco JM, Rekant SI, Arzt J. Effect of storage conditions on subpopulations of peripheral blood T lymphocytes isolated from naive cattle and cattle infected with foot-and-mouth disease virus. Vet Clin Pathol. 2016:45(1):110-5.

52. Stenfeldt C, Pacheco JM, Smoliga GR, Bishop E, Pauszek SJ, Hartwig EJ, Rodriguez LL, Arzt J. Detection of Foot-and-mouth Disease Virus RNA and Capsid Protein in Lymphoid Tissues of Convalescent Pigs Does Not Indicate Existence of a Carrier State. Transbound Emerg Dis. 2014.

53. Callahan JD, Brown F, Osorio FA, Sur JH, Kramer E, Long GW, Lubroth J, Ellis SJ, Shoulars KS, Gaffney KL, et al. Use of a portable real-time reverse transcriptase-polymerase chain reaction assay for rapid detection of footand-mouth disease virus. J Am Vet Med Assoc. 2002;220(11):1636-42.

54. Rasmussen TB, Uttenthal A, De Stricker K, Belak S, Storgaard T. Development of a novel quantitative real-time RT-PCR assay for the simultaneous detection of all serotypes of foot-and-mouth disease virus. Arch Virol. 2003;148(10):2005-21.

55. Weiss DJ, Wardrop KJ. Schalm's Veterinary Hematology. 6th ed. Hoboken: Wiley-Blackwell; 2010.

56. Merck Manual. Hematologic Reference Ranges. In: Aiello SE, editor. The Merck Veterinary Manual. 2012.

57. Ramachandran H, Laux J, Moldovan I, Caspell R, Lehmann PV, Subbramanian RA. Optimal thawing of cryopreserved peripheral blood mononuclear cells for use in high-throughput human immune monitoring studies. Cells. 2012;1(3):313-24.

58. Perfetto SP, Chattopadhyay PK, Lamoreaux L, Nguyen R, Ambrozak D, Koup RA, Roederer M. Amine reactive dyes: an effective tool to discriminate live and dead cells in polychromatic flow cytometry. J Immunol Methods. 2006;313(1-2):199-208.

59. Montes M, Jaensson EA, Orozco AF, Lewis DE, Corry DB. A general method for bead-enhanced quantitation by flow cytometry. J Immunol Methods. 2006:317(1-2):45-55.

60. Hultin LE, Chow M, Jamieson BD, O'Gorman MR, Menendez FA, Borowski L, Denny TN, Margolick JB. Comparison of interlaboratory variation in absolute T-cell counts by single-platform and optimized dual-platform methods. Cytometry B Clin Cytom. 2010;78(3):194-200.

61. Riondato F, D'Angelo A, Miniscalco B, Bellino C, Guglielmino R. Effects of road transportation on lymphocyte subsets in calves. Vet J. 2008;175(3):364-8.

62. LaRocco M, Krug PW, Kramer E, Ahmed Z, Pacheco JM, Duque H, Baxt B, Rodriguez LL. A continuous bovine kidney cell line constitutively expressing bovine alphavbeta6 integrin has increased susceptibility to foot-and-mouth disease virus. J Clin Microbiol. 2013;51(6):1714-20. 
63. LaRocco M, Krug PW, Kramer E, Ahmed Z, Pacheco JM, Duque H, Baxt B, Rodriguez LL, Correction for LaRocco, et al. A Continuous Bovine Kidney Cell Line Constitutively Expressing Bovine alphaVbeta6 Integrin Has Increased Susceptibility to Foot-and-Mouth Disease Virus. J Clin Microbiol. 2015;53(2):755.

64. R: A Language and Environment for Statistical Computing [https://www. R-project.org/]

65. Wickham H. ggplot2: elegant graphics for data analysis. New York: Springer; 2009.

66. Bates D, Maechler M, Bolker BM, Walker S. Ime4: Linear mixed-effects models using Eigen and S4. J Stat Softw. 2014.

67. Moonen P, Jacobs L, Crienen A, Dekker A. Detection of carriers of foot-andmouth disease virus among vaccinated cattle. Vet Microbiol. 2004;103(3-4):151-60.

68. Grubman MJ, Moraes MP, Schutta C, Barrera J, Neilan J, Ettyreddy D, Butman BT, Brough DE, Brake DA. Adenovirus serotype 5-vectored foot-and-mouth disease subunit vaccines: the first decade. Future Virol. 2010;5(1):51-64

69. Pacheco JM, Brum MC, Moraes MP, Golde WT, Grubman MJ. Rapid protection of cattle from direct challenge with foot-and-mouth disease virus (FMDV) by a single inoculation with an adenovirus-vectored FMDV subunit vaccine. Virology. 2005;337(2):205-9.

70. Walton RM. Subject-based reference values: biological variation, individuality, and reference change values. Vet Clin Pathol. 2012;41(2):175-81.

71. Roland L, Drillich M, Iwersen M. Hematology as a diagnostic tool in bovine medicine. J Vet Diagn Invest. 2014;26(5):592-8.

72. Nfon CK, Toka FN, Kenney M, Pacheco JM, Golde WT. Loss of plasmacytoid dendritic cell function coincides with lymphopenia and viremia during footand-mouth disease virus infection. Viral Immunol. 2010;23(1):29-41.

73. Cusick MF, Libbey JE, Fujinami RS. Picornavirus infection leading to immunosuppression. Future Virol. 2014;9(5):475-82.

74. Golde WT, De Los Santos T, Robinson L, Grubman MJ, Sevilla N, Summerfield A, Charleston B. Evidence of activation and suppression during the early immune response to foot-and-mouth disease virus. Transbound Emerg Dis. 2011;58(4):283-90.

75. Ahmed R, Gray D. Immunological memory and protective immunity: understanding their relation. Science. 1996;272(5258):54-60.

76. Janeway C. Basic concepts in immunology. In: Murphy K, Travers P, Walport M, editors. Janeway's Immunobiology. 7th ed. New York: Garland Science; 2008. p. 1-38

77. Sigal LJ, Gomez G, Braun M. Changes in mononuclear peripheral blood cells in cattle with foot-and-mouth disease. Vet Immunol Immunopathol. 1992;30(4):431-8.

78. Shi C, Pamer EG. Monocyte recruitment during infection and inflammation. Nat Rev Immunol. 2011;11(11):762-74.

79. Deshmane SL, Kremlev S, Amini S, Sawaya BE. Monocyte chemoattractant protein-1 (MCP-1): an overview. J Interferon Cytokine Res. 2009;29(6):313-26.

80. McCullough KC, Parkinson D, Crowther JR. Opsonization-enhanced phagocytosis of foot-and-mouth disease virus. Immunology. 1988;65(2):187-91.

81. Quattrocchi V, Langellotti C, Pappalardo JS, Olivera V, Di Giacomo S, Van Rooijen N, Mongini C, Waldner C, Zamorano PI. Role of macrophages in early protective immune responses induced by two vaccines against foot and mouth disease. Antiviral Res. 2011;92(2):262-70.

82. Guzylack-Piriou L, Bergamin F, Gerber M, McCullough KC, Summerfield A. Plasmacytoid dendritic cell activation by foot-and-mouth disease virus requires immune complexes. Eur J Immunol. 2006:36(7):1674-83.

83. McNab F, Mayer-Barber K, Sher A, Wack A, O'Garra A. Type I interferons in infectious disease. Nat Rev Immunol. 2015;15(2):87-103.

84. Tizard IR. Veterinary Immunology. St. Louis: Elsevier Health Sciences; 2013.

85. Toka FN, Kenney MA, Golde WT. Rapid and transient activation of $\gamma \delta$ T cells to IFN- $\gamma$ production, NK cell-like killing, and antigen processing during acute virus infection. J Immunol. 2011;186(8):4853-61.

86. Diaz-San Segundo F, Rodriguez-Calvo T, De Avila A, Sevilla N. Immunosuppression during acute infection with foot-and-mouth disease virus in swine is mediated by IL-10. PLoS ONE. 2009;4(5), e5659.

87. Joshi G, Sharma R, Kakker NK. Phenotypic and functional characterization of T-cells and in vitro replication of FMDV serotypes in bovine lymphocytes. Vaccine. 2009;27(48):6656-61.

88. Abu Elzein EM, Crowther JR. Detection and quantification of $\lg M$, IgA $\lg G 1$ and $\lg G 2$ antibodies against foot-and-mouth disease virus from bovine sera using an enzyme-linked immunosorbent assay. J Hyg (Lond). 1981;86(1):79-85.
89. Mulcahy G, Gale C, Robertson P, lyisan S, DiMarchi RD, Doel TR. Isotype responses of infected, virus-vaccinated and peptide-vaccinated cattle to foot-and-mouth disease virus. Vaccine. 1990;8(3):249-56.

90. Salt JS, Mulcahy G, Kitching RP. Isotype-specific antibody responses to footand-mouth disease virus in sera and secretions of "carrier" and "non-carrier" cattle. Epidemiol Infect. 1996;117(2):349-60.

91. Janeway C. Janeway's Immunobiology. 7th ed. New York: Garland Science; 2008.

92. Eble PL, Bouma A, Weerdmeester K, Stegeman JA, Dekker A. Serological and mucosal immune responses after vaccination and infection with FMDV in pigs. Vaccine. 2007:25(6):1043-54

\section{Submit your next manuscript to BioMed Central and we will help you at every step:}

- We accept pre-submission inquiries

- Our selector tool helps you to find the most relevant journal

- We provide round the clock customer support

- Convenient online submission

- Thorough peer review

- Inclusion in PubMed and all major indexing services

- Maximum visibility for your research

Submit your manuscript at www.biomedcentral.com/submit
Biomed Central 